\title{
WHAT DOES THE YIELD CURVE TELL US ABOUT EXCHANGE RATE PREDICTABILITY?
}

\author{
Yu-chin Chen and Kwok Ping Tsang*
}

\begin{abstract}
Since the term structure of interest rates embodies information about future economic activity, we extract relative Nelson-Siegel (1987) factors from cross-country yield curve differences to proxy expected movements in future exchange rate fundamentals. Using monthly data for the United Kingdom, Canada, Japan, and the United States, we show that the yield curve factors predict exchange rate movements and explain excess currency returns one month to two years ahead. Our results provide support for the asset pricing formulation of exchange rate determination and offer an intuitive explanation to the uncovered interest parity puzzle by relating currency risk premiums to inflation and business cycle risks.
\end{abstract}

\section{Introduction}

$\mathrm{D}$ $\mathrm{O}$ the term structures of interest rates contain information about a country's exchange rate dynamics? This paper shows that the Nelson-Siegel factors extracted from two countries' relative yield curves can predict future exchange rate changes and excess currency returns 1 to 24 months ahead. When the domestic yield curve shifts down or becomes steeper by 1 percentage point relative to the foreign one, home currency can depreciate by $3 \%$ to $4 \%$ over subsequent months. ${ }^{1}$ Its excess return, currency return net of interest differentials, declines by even more. Since the Nelson-Siegel factors have well-known macroeconomic interpretations and capture expected dynamics of future economic activity, our findings provide support for the asset pricing approach of exchange rate determination and imply that the currency risk premiums are driven by differential expectations about countries' future output and inflation, for example. Our results offer an intuitive explanation to the uncovered interest rate (UIP) puzzle.

Decades of exchange rate studies have uncovered many well-known empirical puzzles, in essence failing to connect floating exchange rates to their theoretical macroeconomic determinants, or fundamentals. ${ }^{2}$ From a theoretical standpoint, the nominal exchange rate should be viewed as an asset price; however, the empirical validation of this view remains

Received for publication March 8, 2009. Revision accepted for publication July 8, 2011.

* Chen: University of Washington; Tsang: Virginia Tech.

We thank Vivian Yue for providing us the yield curve data and Charles Nelson, Dani Rodrik, Barbara Rossi, Richard Startz, Wen-Jen Tsay, two anonymous referees, and seminar and conference participants at the San Francisco and Boston Federal Reserve Banks, Duke University, the University of Kansas, and the Bank of Canada-ECB FX Workshop for valuable comments. This work was partly undertaken while Y.-c.C. was a visiting scholar at Academia Sinica, and she gratefully acknowledges its hospitality as well as financial support from the National Science Council of Taiwan.

The online appendices are available at http://www.mitpressjournals.org /doi/suppl/10.1162/REST_a_00231.

${ }^{1}$ When the curvature of the domestic yield curve increases relative to the foreign one, home currency will appreciate subsequently, though the response is not as robust.

${ }^{2}$ Frankel and Rose (1995) offer a comprehensive summary of the various difficulties confronting the empirical exchange rate literature. Sarno (2005) and Rogoff and Stavrakeva (2008) present more recent surveys. elusive. This asset approach is consistent with a range of structural models and relates the nominal exchange rate to the discounted present value of its expected future fundamentals, which can include cross-country differences in money supply, output, and inflation, among others. Because measuring market expectations is difficult, additional assumptions, such as a linear driving process for the fundamentals, are typically imposed in order to relate the exchange rate to its currently observable fundamentals. ${ }^{3}$ The performance of the resulting exchange rate equations is infamously dismal, especially at short time horizons of less than a year or two.

This paper contends that market expectations may be more complicated than what econometricians can capture with the simple driving processes commonly assumed. As such, previous empirical failure may be the result of using inappropriate proxies for market expectations of future fundamentals rather than the failure of the models themselves. We propose an alternative method to capture market expectations and test the asset approach by exploiting information contained in the shapes of the yield curves. Research on the term structure of interest rates has long maintained that the yield curve contains information about expected future economic dynamics, such as monetary policy, output, and inflation. Extending this lesson to the international context, we look at cross-country yield curve differences and extract three Nelson-Siegel (1987) factors-relative level, slope, and curvature- to summarize the expectation information contained therein. The Nelson-Siegel representation has several advantages over the conventional no-arbitrage factor yield curve models. It is flexible enough to adapt to the changing shapes of the yield curve, and the model is parsimonious and easy to estimate. It is also more successful in describing the dynamics of the yield curve over time, which is important to our goal of relating the evolution of the yield curve to movements in the expected exchange rate fundamentals. $^{4}$

We look at three currency pairs over the period August 1985 to July 2005: the Canada dollar, the British pound, and the Japan yen relative to the U.S. dollar. ${ }^{5}$ In addition,

\footnotetext{
${ }^{3}$ See Engel and West (2005) and Mark (1995), among many others.

${ }^{4}$ The no-arbitrage models are often successful in fitting a cross-section of yields but do not do as well in the dynamic setting (Duffee 2002). Diebold, $\mathrm{Li}$, and Yue (2008) show that by imposing an AR(1) structure on the factors, the Nelson-Siegel model has strong forecasting power for future yield curves. In addition, as discussed in Diebold, Rudebusch, and Aruoba (2006), the Nelson-Siegel model avoids potential misspecification due to the presence of temporary arbitrage opportunities in the bonds market.

${ }^{5}$ We note that our results hold also for the other currency pair combinations in our sample. For ease of presentation, we provide results only relative to the U.S. dollar in this paper.
} 
with a different data set, we present corroborating results for a more recent period-between January 1991 and May 2011. Using zero-coupon yield data, we fit the three NelsonSiegel relative factors to the yield differences between the three countries and the United States at maturities ranging from three months to ten years. Our results show that all three relative yield curve factors can help predict bilateral exchange rate movements and explain excess currency returns one month to two years ahead, with the slope factor being the most robust across currencies. We find that a 1 percentage point rise in the slope or level factors of one country relative to another produces an annualized 3\% to $4 \%$ appreciation of its currency subsequently, with the magnitude of the effect declining over the horizon. The responses of excess currency returns tend to be even larger. Movements in the curvature factor have a much smaller effect on exchange rates of roughly one-to-one, and they are also the least robust. We pay special attention to addressing the inference bias inevitable in our small sample long-horizon regressions, which we discuss in more detail in section III. ${ }^{6}$

Tying floating exchange rates to macroeconomic fundamentals has been a long-standing struggle in international finance. Our results suggest that to the extent that the yield curve is shaped by market expectations regarding future macroeconomic fundamentals, exchange rate movements are not disconnected from fundamentals but relate to them via a present value asset pricing relation. Moreover, our results have straightforward economic interpretations and offer insight into the uncovered interest parity puzzle: the empirical regularity that the currencies of high interest rate countries tend to appreciate subsequently rather than depreciate according to the foreign exchange market efficient condition. In particular, we find that deviations from UIP-excess currency returns-systematically respond to the shape of the yield curves, which in turn capture market perception of future inflation, output, and other macro indicators. ${ }^{7}$ Take, for example, our results showing that a flatter relative yield curve or an upward shift in its overall level predicts subsequent home currency appreciation and a high home currency risk premium. Since the flattening of the yield curve is typically considered a signal for an economic slowdown or a forthcoming recession, a flat domestic yield curve relative to the foreign one suggests that the expected future growth at home is relatively low. In accordance with the present value relation, home currency faces depreciation pressure as investors pull out and, ceteris paribus, appreci-

\footnotetext{
${ }^{6}$ To complement results presented in the main text, we also conduct rolling out-of-sample forecasts to see how our yield curve model forecasts future exchange rate changes relative to the random walk forecasts and also forecasts based on interest differentials of a single maturity. Our model does not consistently outperform the two benchmarks considered. See the online appendix for details.

${ }^{7}$ Deviations from UIP reflect both currency risk premium and expectation errors. For presentational simplicity, we assume away systematic expectation errors here, though they are clearly present empirically and our analyses would carry through without making this assumption (see Froot \& Frankel, 1989, and Chen, Tsang, \& Tsay, 2010).
}

ates over time toward its long-term equilibrium value. ${ }^{8} \mathrm{~A}$ similar explanation can also be applied to the case of a large level factor, which reflects high expected future inflation. Both of these scenarios can induce higher perceived risk associated with holding the domestic currency, as its payoff would be negatively correlated with the marginal utility of consumption. This explains our observed rise in excess home currency returns-the risk premium associated with domestic currency holding.

The above intuition has clear implications for the UIP puzzle. Since a rise in the short-term interest rate flattens the slope of the yield curve or raises its overall level, both would imply a risk-premium increase. The home currency may thus appreciate subsequently instead of depreciate according to UIP if the risk premium adjustment is large enough. Although we do not explicitly model expectations and perceived risks in this paper, our results are in accordance with simple economic intuitions. In fact, we show that by augmenting standard UIP regressions with longermaturity rates, the UIP puzzle can disappear. This suggests the puzzle is related to an omitted risk premium term embodied in the rest of the yield curves.

Using data from the Survey of Professional Forecasters, we provide empirical support for the view that the U.S. yield curve factors are highly correlated, in the directions discussed above, with investors' reported expectations about future GDP growth and inflation in the United States, as well as with their reported levels of anxiety about an impending economic downturn. ${ }^{9}$ Given their ability to capture market expectations, we conjecture that the success of the yield curve factors in predicting exchange rates may also be attributable to their real-time nature. Molodtsova, Nikolsko-Rzhevsky, and Papell (2008), for instance, estimate Taylor rules for Germany and the United States and find strong evidence that higher inflation predicts exchange rate appreciation using real-time data but not revised data. Finally, we note that our approach is consistent with previous research using the term structure of the exchange rate forward premiums or the relative yield spreads to predict future spot exchange rate, such as Frankel (1979), Clarida and Taylor (1997), and Clarida et al (2003). ${ }^{10}$ Yield differences relate to exchange rate forwards via the covered interest parity condition. However, given that the exchange rate

\footnotetext{
${ }^{8}$ We note that this finding is contrary to the classic Dornbusch (1976) overshooting model, which predicts an immediate currency appreciation and subsequent depreciation in response to a higher interest rate. Our result is consistent with observations made in more recent papers, such as Eichenbaum and Evans (1995), Gourinchas and Tornell (2004), and Clarida and Waldman (2008).

${ }^{9}$ We limit the analysis here to the United States because comparable high-quality survey data are more difficult to obtain for the other countries. We explore the role of surveyed expectations more fully in Chen et al. (2010).

${ }^{10}$ Frankel (1979) incorporates long-term interest rates, proxying for long-term inflation, in exchange rate models. Clarida et al. (2003) find that the term structure of forward premiums can forecast future spot rates. See also Boudoukh, Richardson, and Whitelaw (2005) and de los Rios (2009).
} 
forwards are available up to only a year or so, our yield curve approach can capture a much wider range of relevant market information by looking at yields all the way up to ten years or beyond. ${ }^{11}$

\section{The Exchange Rates and the Yield Curves}

Both the exchange rate and the yield curve rest atop decades of prodigious research. This paper makes no pretense of offering a comprehensive framework for jointly modeling the two, though we do believe this is a worthwhile endeavor. ${ }^{12}$ In this section, we first present the standard workhorse approach to modeling the nominal exchange rate as an asset price. We then propose that progress in the yield curve literature, namely, the empirical evidence that yield curves embody information about expected future dynamics of key macroeconomic variables, can help improve on the approach used in previous exchange rate estimations. Next, we offer a brief presentation of the Nelson-Siegel yield curve factors as a parsimonious way to capture the information in the entire yield curve while having a well-established connection with macroeconomic variables. Finally, we present a short discussion on excess returns and risk premium, connecting our findings to the UIP literature.

\section{A. The Present Value Model of Exchange Rate}

The asset approach to exchange rate determination models the nominal exchange rate as the discounted present value of its expected future fundamentals, such as crosscountry differences in monetary policy, output, and inflation. This present-value relation can be derived from various exchange rate models that linearly relate log exchange rate, $s_{t}$, to its $\log$ fundamental determinants, $f_{t}$, and its expected future value $E_{t} s_{t+1}$. The first classical example is the workhorse monetary model developed by Mussa (1976) and explored extensively in subsequent papers. Based on money market equilibrium, uncovered interest parity, and purchasing power parity, the monetary model can be expressed as

$$
s_{t}=\gamma f_{t}+\psi E_{t} s_{t+1},
$$

where $f_{t}=\left(m_{t}-m_{t}^{*}\right)-\phi\left(y_{t}-y_{t}^{*}\right), m$ is money stock, $y$ is output, * denotes foreign variables, and $\phi, \gamma, \psi$ (as well as $\lambda$ below) are parameters related to the income and interest elasticities of money demand. Variations of the monetary

\footnotetext{
${ }^{11}$ Our Nelson-Siegel framework is also more comprehensive than using only the term spreads (for example, the difference between ten-year Treasury notes and three-month Treasury bills).

${ }_{12}$ Bekaert, Wei, and Xing (2007) and Wu (2007) are recent examples that attempt to jointly analyze the uncovered interest parity and the expectation hypothesis of the term structure of interest rates. On the finance side, recent efforts using arbitrage-free affine or quadratic factor models have also shown success in connecting the term structure with the dynamics of exchange rates (see Inci \& Lu, 2004). In contrast to these papers, our work here emphasizes the macroeconomic connections between the yield curves and the exchange rates through the use of the Nelson-Siegel factors. Chen and Tsang (2009) present a macro-finance model of the exchange rate.
}

model that capture price rigidities and short-term liquidity effects expand the set of fundamentals to $f_{t}^{M}=$ $\left(m_{t}-m_{t}^{*}\right)-\beta_{y}\left(y_{t}-y_{t}^{*}\right)-\beta_{i}\left(i_{t}-i_{t}^{*}\right)+\beta_{\pi}\left(\pi_{t}-\pi_{t}^{*}\right)$, as in Frankel (1979). Solving equation (1) forward and imposing the appropriate transversality condition, the nominal exchange rate has the standard asset price expression, based on information $I_{t}$ at time $t$ :

$$
s_{t}=\lambda \sum_{j=0}^{\infty} \psi^{j} E_{t}\left(f_{t+1} \mid I_{t}\right)
$$

This present value expression, with alternative sets of model-dependent fundamentals, serves as the starting point for standard textbook treatments and for many major contributions to the empirical exchange rate literature (Mark, 1995; Engel \& West, 2005).

Several recent papers emphasize the importance of monetary policy rules, especially the Taylor rule, in modeling exchange rates. ${ }^{13}$ The Taylor rule model assumes that the monetary policy instruments, the home interest rate $i_{t}$ and the foreign rate $i_{t}^{*}$, are set as follows:

$$
\begin{aligned}
& i_{t}=\mu_{t}+\beta_{y} y_{t}^{\text {gap }}+\beta_{\pi} \pi_{t}^{e}, \\
& i_{t}^{*}=\mu_{t}^{*}+\beta_{y} y_{t}^{*, g a p}+\beta_{\pi} \pi_{t}^{*, e}-\delta q_{t},
\end{aligned}
$$

where $y_{t}^{\text {gap }}$ is the output gap, $\pi_{t}^{e}$ is the expected inflation, $\beta_{y}$, $\beta_{\pi}, \delta>0$, and $\mu_{t}$ contains the inflation and output targets, the equilibrium real interest rate, and other omitted terms. The foreign corresponding variables are denoted with an asterisk, and following the literature, we assume the foreign central bank to explicitly target the real exchange rate or purchasing power parity $q_{t}=s_{t}-p_{t}+p_{t}^{*}$ in addition, with $p$ denoting the overall price level. ${ }^{14}$ The efficient market condition for the foreign exchange markets, under rational expectations, equates cross-border interest differentials $i_{t}-$ $i_{t}^{*}$ with the expected rate of home currency depreciation, adjusted for the risk premium associated with home currency holdings, $\rho^{H}$ :

$$
i_{t}-i_{t}^{*}=E_{t} \Delta s_{t+1}+\rho_{t}^{H} .
$$

Combining equations (3) and (4) and letting $v_{t}=\mu_{t}-\mu_{t}^{*}$, we have:

$$
\begin{aligned}
& \beta_{y}\left(y_{t}^{\text {gap }}-y_{t}^{* \text { gap }}\right)+\beta_{\pi}\left(\pi_{t}^{e}-\pi_{t}^{*, e}\right) \\
& \quad+\delta\left(s_{t}-p_{t}+p_{t}^{*}\right)+v_{t}=E_{t} \Delta s_{t+1}+\rho_{t}^{H} .
\end{aligned}
$$

Solving for $s_{t}$ and rearranging terms, we arrive at an expression equivalent to equation (1), with a different set of fundamentals $f_{t}^{T R 1}$ :

\footnotetext{
${ }^{13}$ See Engel and West (2005), Molodtsova and Papell (2008), and Wang and $\mathrm{Wu}(2009)$ as examples.

${ }^{14}$ For notation simplicity, we assume the home and foreign central banks to have the same weights $\beta_{y}$ and $\beta_{\pi}$.
} 


$$
\begin{aligned}
s_{t}= & \frac{\delta}{1+\delta}\left(p_{t}-p_{t}^{*}\right)-\frac{1}{1+\delta}\left\{\beta_{y}\left(y_{t}^{\text {gap }}-y_{t}^{*, g a p}\right)\right. \\
& \left.+\beta_{\pi}\left(\pi_{t}^{e}-\pi_{t}^{*, e}\right)-\rho_{t}^{H}+v_{t}\right\}+\frac{1}{1+\delta} E_{t} s_{t+1} .
\end{aligned}
$$

Here $f_{t}^{T R 1}=\left\{\left(p_{t}-p_{t}^{*}\right),\left(y_{t}^{\text {gap }}-y_{t}^{*, g a p}\right),\left(\pi_{t}^{e}-\pi_{t}^{*, e}\right), \rho_{t}^{H}\right\}$. As Engel and West pointed out (2005), equation (6) can be reexpressed in the same general form as equation (1) but with yet a different set of fundamentals $f_{t}^{T R 2}$ :

$$
\begin{aligned}
s_{t}= & \delta\left(i_{t}-i_{t}^{*}\right)+\delta\left(p_{t}-p_{t}^{*}\right)-\beta_{y}\left(y_{t}^{\text {gap }}-y_{t}^{*, g a p}\right) \\
& -\beta_{\pi}\left(\pi_{t}^{*}-\pi_{t}^{*, e}\right)+(1-\delta) \rho_{t}^{H}-v_{t}+(1-\delta) E_{t} s_{t+1},
\end{aligned}
$$

with $f_{t}^{T R 2}=\left\{\left(i_{t}-i_{t}^{*}\right),\left(p_{t}-p_{t}^{*}\right),\left(y_{t}^{g a p}-y_{t}^{*, g a p}\right),\left(\pi_{t}^{e}-\pi_{t}^{*, e}\right)\right.$, $\left.\rho_{t}^{H}\right\}$. Both equations (6) and (7) can be solved forward, leading to the asset pricing equation (2) with a different set of fundamentals $f_{t}^{T R 1}$ or $f_{t}^{T R 2}$.

Various structural exchange rate models, classical or Taylor rule-based, can deliver the net present value equation where the exchange rate is determined by expected future values of cross-country output, inflation, and interest rates. As we show in the next section, these are exactly the macroeconomic indicators for which the yield curves appear to embody information.

Empirically, the nominal exchange rate is best approximated by a unit root process, so we express equation (2) in a first-differenced form ( $\varepsilon$ is expectation error):

$$
\Delta s_{t+1}=\lambda \sum_{j=1}^{\infty} \psi^{j} E_{t}\left(\Delta f_{t+j} \mid I_{t}\right)+\varepsilon_{t+1} .
$$

From here on, we deviate from the common approach in the literature that imposes additional assumptions on the statistical processes driving the fundamentals. Instead, we use the information in the yield curves to proxy the expected discounted sum on the right-hand side of equation (8). ${ }^{15}$

\section{B. The Yield Curve and the Nelson-Siegel Factors}

The yield curve or the term structure of interest rates describes the relationship between yields and their time to maturity. Traditional models of the yield curve posit that its shape is determined by expected future paths of interest rates and perceived future uncertainty (the risk premia). While the classic expectations hypothesis is rejected frequently, research on the term structure of interest rates has convincingly demonstrated that the yield curve contains information about expected future economic conditions, such as output growth and inflation. ${ }^{16}$ Below we give a brief summary

\footnotetext{
${ }^{15}$ Previous literature has attempted to use surveyed market expectations as an alternative. See Frankel and Rose (1995), Sarno (2005), and Chen et al. (2010) for more discussion.

${ }^{16}$ The expectations hypothesis expresses a long yield of maturity $m$ as the average of the current one-period yield and the expected one-period yields for the upcoming $m-1$ periods, plus a term premium. See Thornton (2006).
}

of the Nelson-Siegel (1987) framework for characterizing the shape of the yield curve and motivate our use of the relative factors. We then summarize the findings of the macrofinance literature regarding the factors' predictive content.

The Nelson-Siegel (1987) factors offer a succinct approach to characterize the shape of the yield curve in the following form, ${ }^{17}$

$$
i_{t}^{m}=L_{t}+S_{t}\left(\frac{1-e^{-\lambda m}}{\lambda m}\right)+C_{t}\left(\frac{1-e^{-\lambda m}}{\lambda m}-e^{-\lambda m}\right),
$$

where $i_{t}^{m}$ is the continuously compounded zero-coupon nominal yield on an $m$-month bond and parameter $\lambda$ controls the speed of exponential decay. ${ }^{18}$ The three factors $L_{t}, S_{t}$, and $C_{t}$ typically capture most of the information in a yield curve, with $R^{2}$ usually close to 0.99 .

\section{The Yield Curve-Macro Linkage}

There is a long history of using the term structure to predict output and inflation. ${ }^{19}$ Mishkin (1990a, 1990b) shows that the yield curve predicts inflation and that movements in the longer end of the yield curve are mainly explained by changes in expected inflation. Barr and Campbell (1997) use data from U.K. index-linked bonds and show that longterm expected inflation explains almost $80 \%$ of the movement in long yields. Estrella and Mishkin (1998) show that the term spread is correlated with the probability of a recession, and Hamilton and Kim (2002) find that it can forecast GDP growth.

The more recent macro-finance literature connects the observation that the short rate is a monetary policy instrument with the idea that yields of all maturities are riskadjusted averages of expected short rates. This more structural approach offers deeper insight into the relationship between the yield curve factors and macroeconomic dynamics. ${ }^{20}$ Ang, Piazzesi, and Wei (2006) find that the term spread (the slope factor) and the short rate (the sum of level and slope factors) outperform a simple AR(1) model in forecasting GDP growth four to twelve quarters ahead. Using a New Keynesian model, Bekaert, Cho, and Moreno (2010) demonstrate that the level factor is mainly moved by changes in the central bank's inflation target, and monetary policy shocks dominate the movements in the slope and curvature factors. Dewachter and Lyrio (2006) estimate an

\footnotetext{
${ }^{17}$ Nelson-Siegel (1987) derive the factors by approximating the forward rate curve at a given time with a Laguerre function that is the product of a polynomial and an exponential decay term. This forward rate is the (equal-root) solution to the second-order differential equation for the spot rates. A parsimonious approximation of the yield curve can then be obtained by averaging over the forward rates. The resulting function is capable of capturing the relevant shapes of the empirically observed yield curves: monotonic, humped, or S-shaped.

${ }^{18}$ We use zero-coupon bonds to avoid the coupon effect and the Treasuries to abstract away from default risks and liquidity concerns. Parameter $\lambda$ is set to 0.0609 as is standard in the literature.

${ }^{19}$ See Estrella (2005) for a survey and explanations for why the yield curve predicts output and inflation.

${ }^{20}$ See Diebold, Piazzesi, and Rudebusch (2005) for a short survey.
} 
affine model for the yield curve with macroeconomic variables. They find that the level factor reflects agents' long-run inflation expectation, the slope factor captures the business cycle, and the curvature represents the monetary stance of the central bank. Finally, Rudebusch and Wu $(2007,2008)$ contend that the level factor incorporates long-term inflation expectations, and the slope factor captures the central bank's dual mandate of stabilizing the real economy and keeping inflation close to its target. They provide macroeconomic underpinnings for the factors and show that when agents perceive an increase in the long-run inflation target, the level factor will rise and the whole yield curve will shift up. The slope factor is modeled using a Taylor rule, reacting to the output gap $y_{t}^{\text {gap }}$ and inflation $\pi_{t}$. When the central bank tightens monetary policy, the slope factor rises, forecasting lower growth in the future. ${ }^{21}$ To capture the arguments in the vast literature above, we provide a simple illustrative example of how the level and slope factors incorporate expectations of future inflation and output dynamics in Appendix A1 (the appendices are in the online supplement).

Noting that the exchange rate fundamentals $\left(f_{t}^{M}, f_{t}^{T R 1}\right.$, or $f_{t}^{T R 2}$ ) discussed in section II.A are in cross-country differences, we propose to measure the discounted present value on the right-hand side of equation (8) with the cross-country differences in their yield curves. Assuming symmetry and exploiting the linearity in the factor loadings in equation (9), we fit three Nelson-Siegel factors of the relative level $\left(L_{t}^{R}\right)$, the relative slope $\left(S_{t}^{R}\right)$, and the relative curvature $\left(C_{t}^{R}\right)$ as follows:

$$
\begin{aligned}
i_{t}^{m}-i_{t}^{m *}= & L_{t}^{R}+S_{t}^{R}\left(\frac{1-e^{-\lambda m}}{\lambda m}\right) \\
& +C_{t}^{R}\left(\frac{1-e^{-\lambda m}}{\lambda m}-e^{-\lambda m}\right)+\varepsilon_{t}^{m},
\end{aligned}
$$

where $\varepsilon_{t}^{m}$ is fitting error. The relative factors, $L_{t}^{R}, S_{t}^{R}$, and $C_{t}^{R}$, serve as a proxy for expected future fundamentals in our exchange rate regressions. (We note that $i_{t}^{m}$ is defined as the U.S. or home yield, so the relative factors are defined from the perspective of the United States relative to the other countries.)

\section{Excess Currency Returns and the Risk Premium}

To gain further insight into the UIP puzzle, we examine how excess returns respond to expectations about future macroeconomic dynamics. Excess return, defined here for the foreign currency, is the difference in the cross-country yields adjusting for the relative currency movements:

$$
r x_{t+m}=i_{t}^{m *}-i_{t}^{m}+\Delta s_{t+m},
$$

where the last term represents the percentage appreciation of foreign currency.

Under the assumptions that on aggregate, foreign exchange market participants are risk neutral and have

\footnotetext{
${ }^{21}$ The literature does not provide a clear interpretation of the curvature factor, so we do not emphasize its macroeconomic linkage.
}

rational expectations, the efficient market condition for the foreign exchange market equates expected exchange rate changes to cross-country interest rate differences over the same horizon; this is the UIP condition. In ex post data, however, UIP is systematically violated over a wide range of currency-interest rate pairs as well as frequencies. The leading explanations for this UIP puzzle point to either the presence of time-varying risk premiums or systematic expectation errors. ${ }^{22}$ We note that under the assumption of rational expectations, excess return in equation (11) represents the risk premium associated with foreign currency holdings, $\rho^{F}$, as expressed below:

$$
\Delta s_{t+m}-\left(i_{t}^{m}-i_{t}^{m *}\right)=\rho_{t+m}^{F}+\varepsilon_{t+m}=r x_{t+m}
$$

where $\varepsilon_{t+m}$ represents expectation error and would-be white noise under rational expectations. ${ }^{23}$ We examine how the risk premium adjusts to market expectations about future relative macroeconomic dynamics, as captured by the relative factors.

\section{Data and Estimation Strategies}

\section{A. Data Description}

Our main sample consists of monthly data from August 1985 to July 2005 for the United States, Canada, Japan, and the United Kingdom of the following series:

- Zero-coupon bond yields for maturities 3, 6, 9, 12, 15, $18,21,24,30,36,48,6072,84,96,108$, and 120 months, where the yields are computed using the FamaBliss (1987) methodology. The data set is from Diebold, $\mathrm{Li}$, and Yue (2008), and we use three-month Treasury bills from Global Financial Data to fill in some of the missing observations.

- Exchange rate measured as the U.S. dollar price per unit of the foreign currency. ${ }^{24} \mathrm{~A}$ lower number means an appreciation of the home currency, the USD. For all horizons, we define exchange rate change as the annualized change of the log exchange rate $s$.

To supplement our main results and see whether our findings are robust over the financial crisis of 2008 , we also use data covering January 1991 to May 2011, which we obtain from the Bank of Canada, Bank of England, and the Federal Reserve Economic Data (we do not have data on Japan).

We estimate equation (10) by OLS period by period to obtain times series of the relative Nelson-Siegel factors, $L_{t}^{R}$, $S_{t}^{R}$, and $C_{t}^{R}$, for Canada, Japan, and the United Kingdom,

\footnotetext{
22 The peso problem is also a common explanation. See Engel (1996) and Sarno (2005) for surveys.

23 If we relax the assumption of rational expectations, $\rho^{F}$ would then represent both risk premium and expectation errors.

${ }^{24}$ The yields are reported for the second day of each month. We match the yield data at time $t$ with the exchange rate of the last day of the previous month (two days earlier).
} 
Figure 1.-Exchange Rates and Relative Factors

A. Canada

Canadian- US Exchange Rate and Relative Level Factor

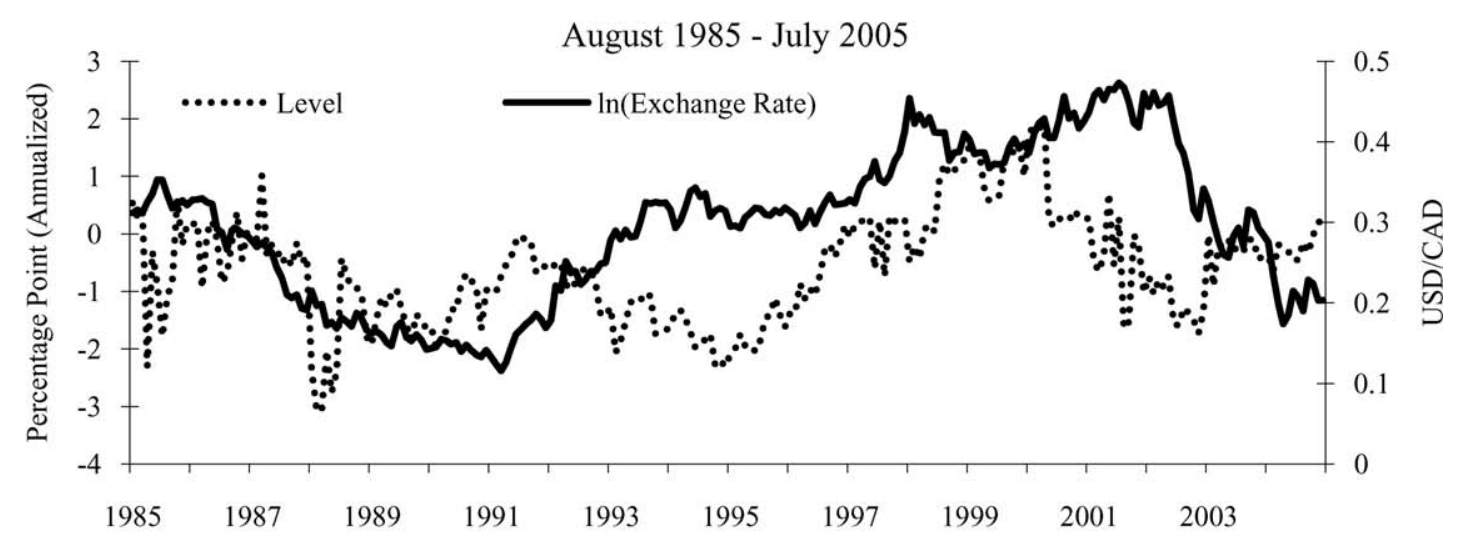

Canadian- US Exchange Rate and Relative Slope Factor

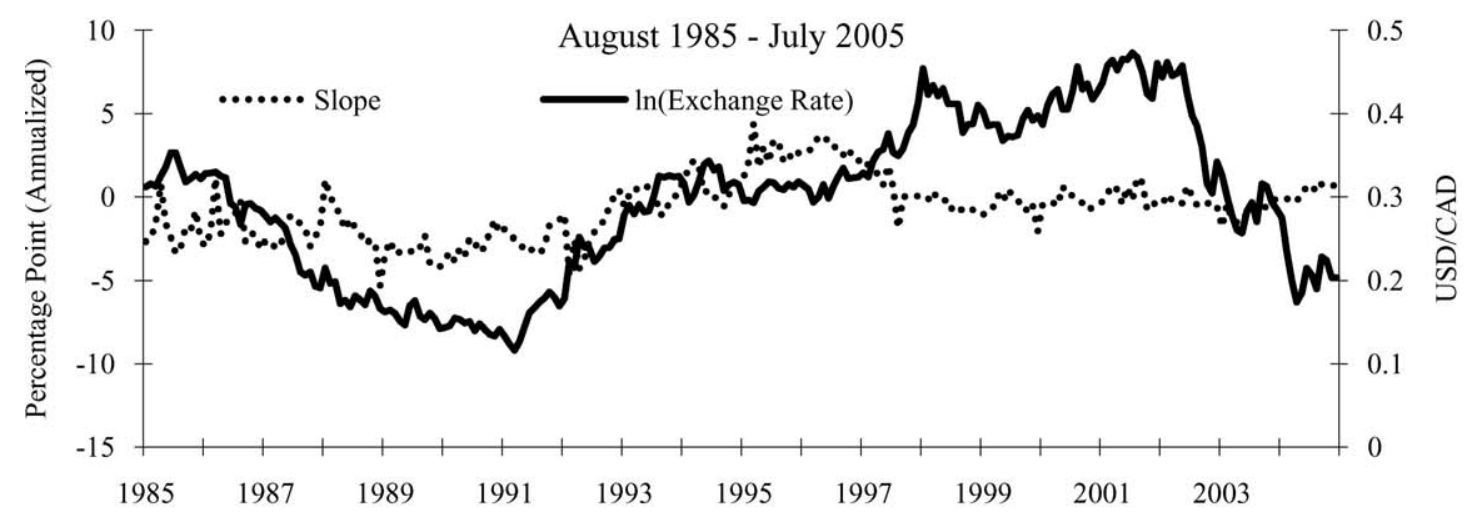

Canadian- US Exchange Rate and Relative Curvature Factor

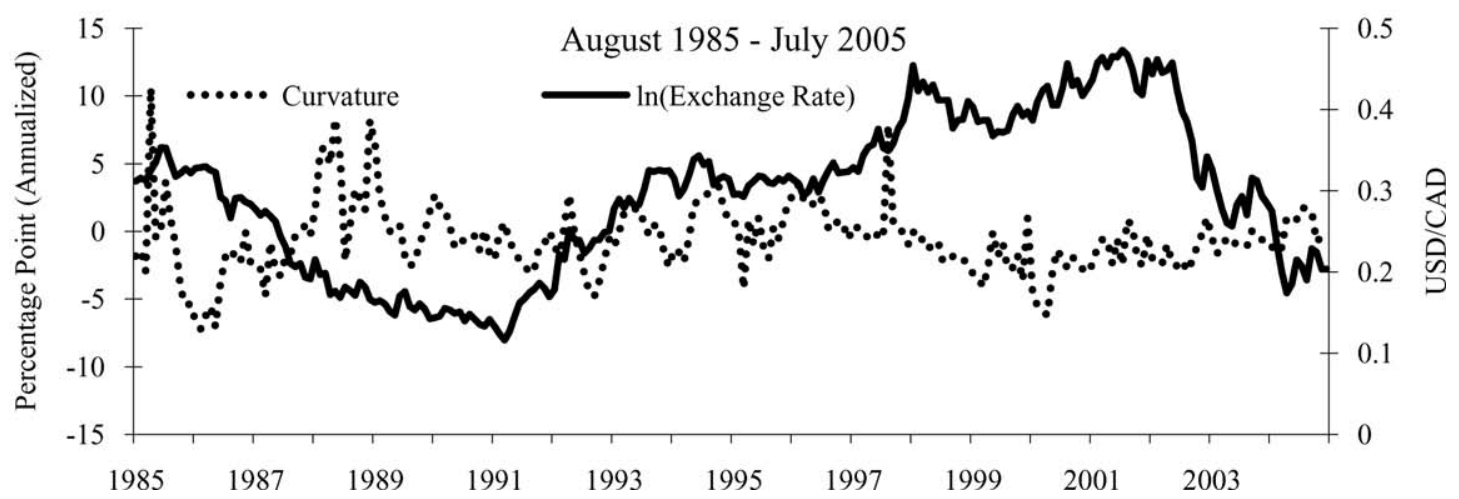

relative to the United States. We plot the relative factors with the log exchange rates in figures $1 \mathrm{~A}$ to $1 \mathrm{C}$ and report their summary statistics in the first half of table $1 .^{25}$

The relative factors behave somewhat differently from the typical single-country Nelson-Siegel factors, as ex-

\footnotetext{
${ }^{25}$ We note that the augmented Dickey-Fuller test of Elliott, Rothenberg, and Stock (1996) rejects the presence of a unit root in all of the relative factors, exchange rate changes, and excess return series.
}

pected. The relative level factor has low persistence and small volatility. Unlike the single-country slope factor which is typically very noisy, it is difficult to visually distinguish the relative slope factor from the relative level factor. The relative curvature factor is the most volatile, as with the single-country curvature. There are also some noticeable differences across countries in their coefficients of variation ( $\mathrm{SD} / \mathrm{mean})$. For example, Japan's relative level has a much higher mean and is also much less varied, 


$$
\text { Figure 1.-(CONTINUED) }
$$

B. JAPAN

Japan- US Exchange Rate and Relative Level Factor

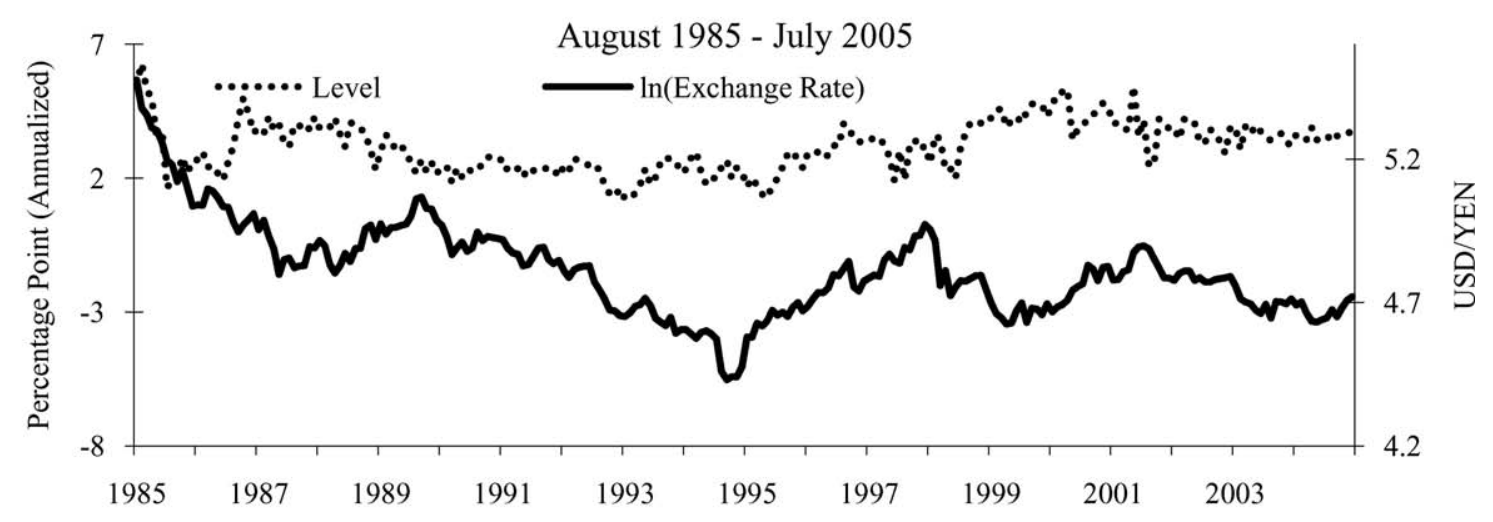

Japan- US Exchange Rate and Relative Slope Factor

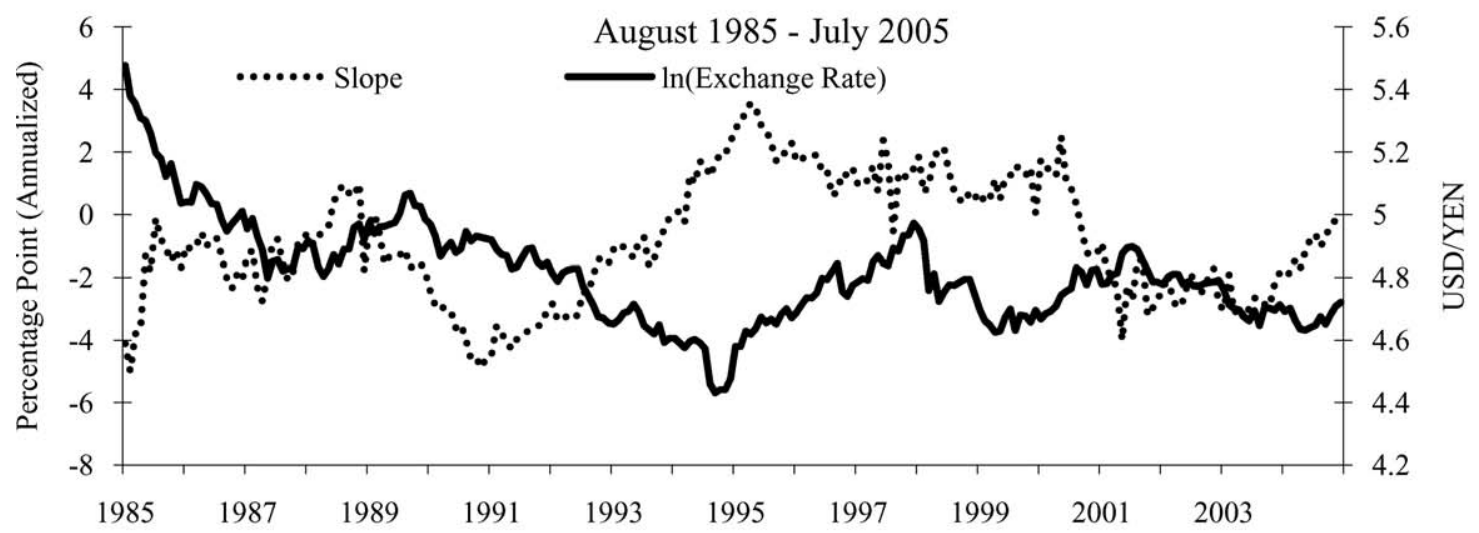

Japan- US Exchange Rate and Relative Curvature Factor

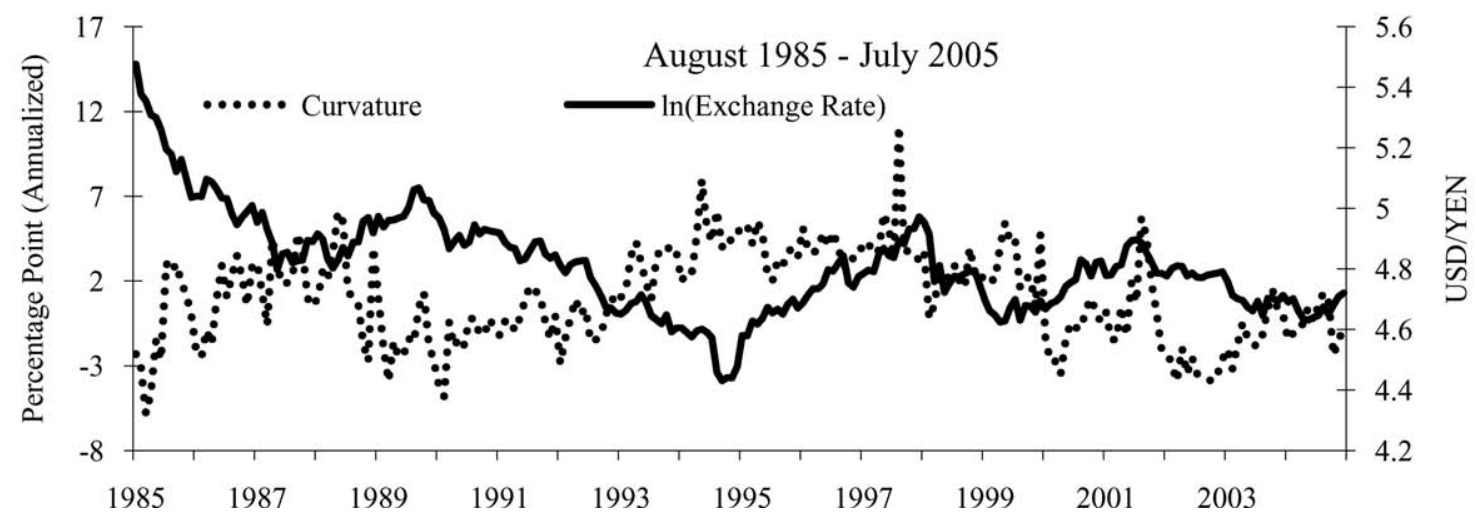

whereas the United Kingdom has a volatile curvature factor. Correlation coefficients among the nine relative factors are reported in the second half of table 1 . We note that factors across countries are positively correlated, especially for the level and slope factors. This is likely due to the presence of the U.S. yield curve in each of these country pairs. ${ }^{26}$

\footnotetext{
${ }^{26}$ We note again that our conclusions extend to non-U.S. dollar country pairs.
}

Within each country, the three factors are also correlated, but there is no consistent pattern.

Finally, excess currency return is computed as

$$
r x_{t+m}=i_{t}^{m *}-i_{t}^{m}+\Delta s_{t+m},
$$

where $m$ is the horizon measured in months. As discussed above, this measures the annualized percentage return from both interest differentials and currency appreciation and represents the risk premium associated with holding foreign 

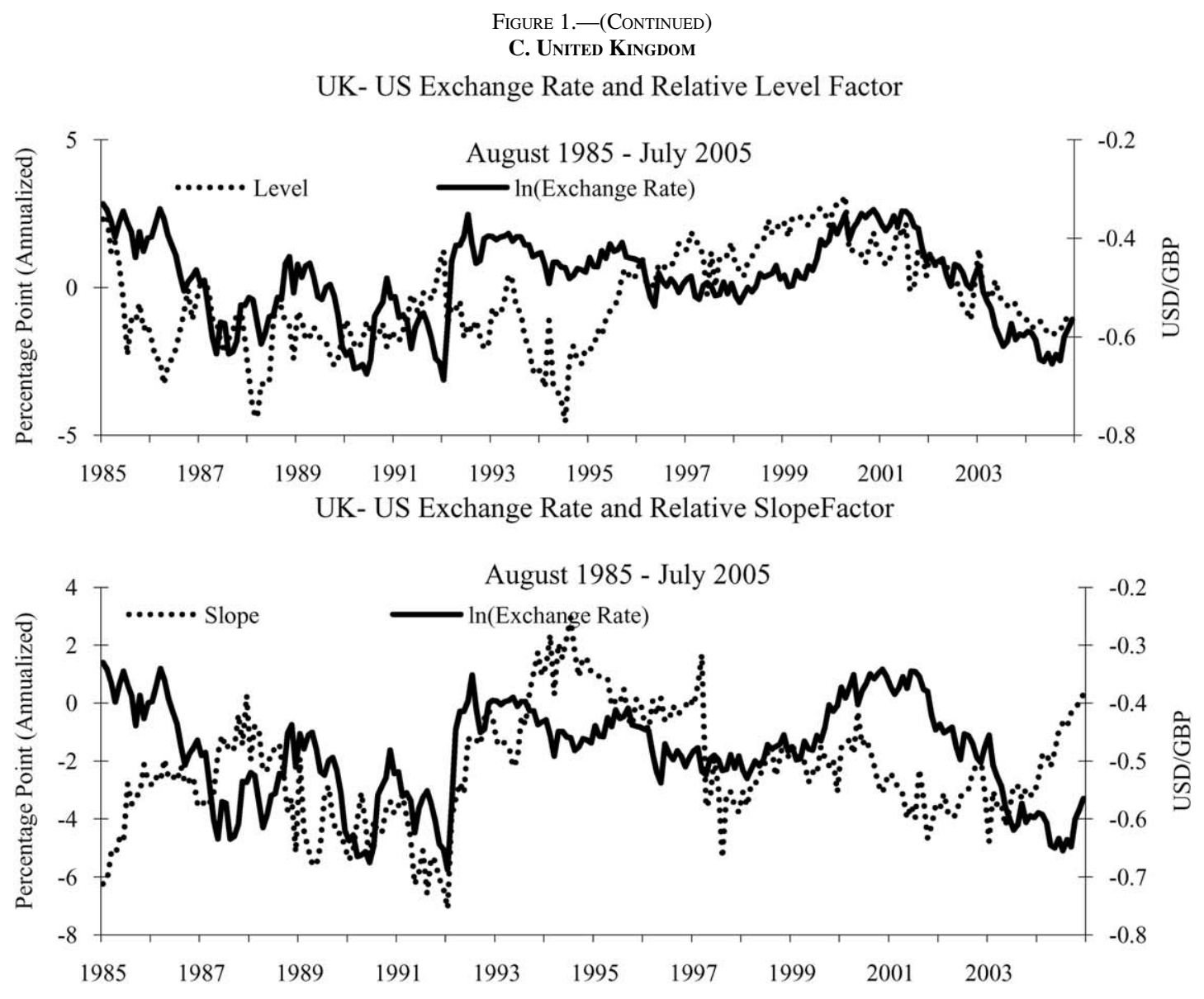

UK- US Exchange Rate and Relative Curvature Factor

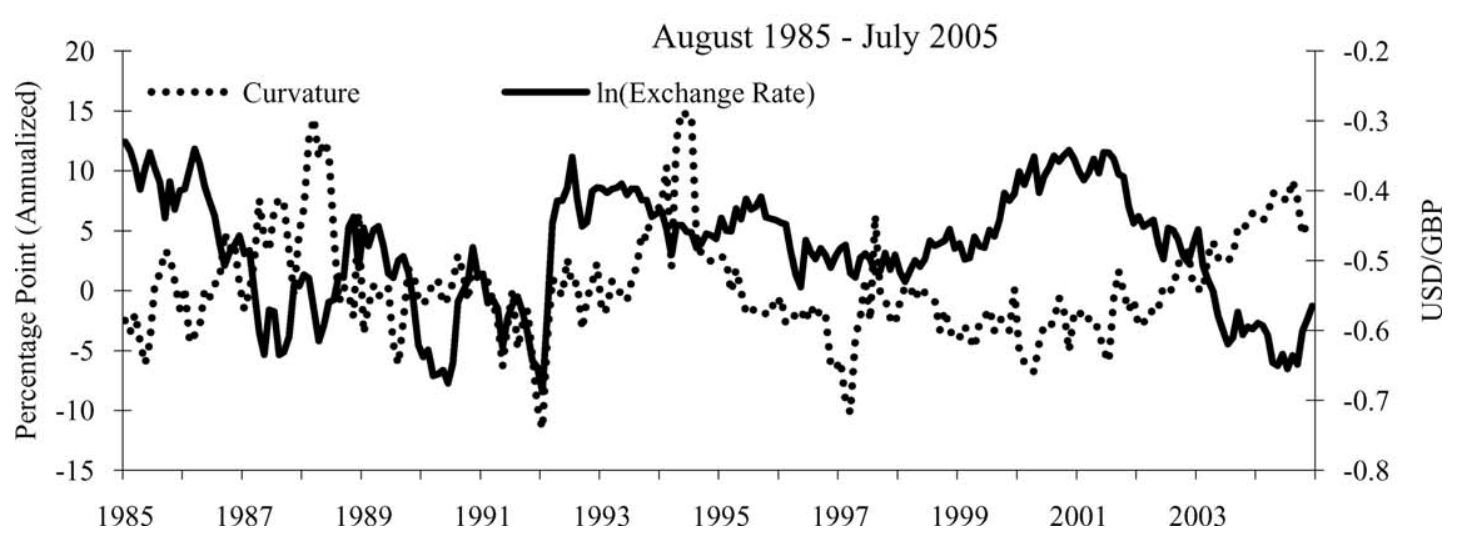

The term structure factors for each country are calculated by the following procedure. In each period, we subtract the yields of each country from those of the United States, matching the maturities. We then fit the Nelson-Siegel yield curve on the yield differences and obtain the level, slope, and curvature factors for that period.

currency (under the assumption of no systematic expectation errors, as discussed earlier).

\section{B. Yield Curve Factors and Surveyed Expectations}

Section II summarized prior research showing the term structure factors as a robust and powerful predictor for future macroeconomic dynamics. We conduct some simple tests here using our U.S. yield curve data and the Survey of Professional Forecasters (SPF), which contains forecasts of a wide range of economic indicators for the United States from a large group of private sector and institutional economists. ${ }^{27}$ We take the mean forecasts for real GDP growth and CPI inflation for horizons from one to four quarters ahead and correlate them with the current yield curve factors. We also check the correspondence of the Anxious

\footnotetext{
${ }^{27}$ We note that comparably reliable surveyed expectation data are difficult to obtain for the other countries in our paper; hence, this section looks at the United States only.
} 
Table 1.-Summary Statistics and Correlations for the Relative Factors

\begin{tabular}{|c|c|c|c|c|c|c|c|c|c|}
\hline \multicolumn{10}{|l|}{ A. Summary Statistics } \\
\hline & \multicolumn{3}{|c|}{ Relative Level L ${ }^{\mathrm{R}}$} & \multicolumn{3}{|c|}{ Relative Slope $S^{\mathrm{R}}$} & \multicolumn{3}{|c|}{ Relative Curvature $C^{\mathrm{R}}$} \\
\hline & Canada & Japan & $\begin{array}{c}\text { United } \\
\text { Kingdom }\end{array}$ & Canada & Japan & $\begin{array}{c}\text { United } \\
\text { Kingdom }\end{array}$ & Canada & Japan & $\begin{array}{l}\text { United } \\
\text { Kingdom }\end{array}$ \\
\hline Mean & -0.599 & 3.179 & -0.395 & -0.678 & -0.826 & -2.273 & -0.611 & 1.055 & 0.417 \\
\hline Median & -0.598 & 3.208 & -0.591 & -0.515 & -1.017 & -2.446 & -0.740 & 1.014 & -0.260 \\
\hline Maximum & 2.000 & 6.279 & 3.110 & 4.406 & 3.567 & 2.946 & 10.589 & 11.138 & 14.938 \\
\hline Minimum & -3.076 & 1.225 & -4.560 & -5.306 & -4.997 & -7.097 & -7.205 & -5.821 & -11.563 \\
\hline SD & 0.969 & 0.947 & 1.604 & 1.827 & 1.955 & 1.933 & 2.561 & 2.754 & 4.476 \\
\hline Skewness & 0.215 & 0.224 & 0.032 & 0.207 & 0.063 & 0.159 & 0.771 & 0.108 & 0.809 \\
\hline Kurtosis & 2.906 & 2.663 & 2.412 & 2.752 & 2.116 & 2.784 & 5.660 & 2.721 & 4.264 \\
\hline \multicolumn{10}{|c|}{ B. Correlations between Relative Factors } \\
\hline & $\mathrm{L}^{\mathrm{R}}$ & $\mathrm{L}^{\mathrm{R}}$ & $\mathrm{L}^{\mathrm{R}}$ & $\mathrm{S}^{\mathrm{R}}$ & $\mathrm{S}^{\mathrm{R}}$ & $\mathrm{S}^{\mathrm{R}}$ & $\mathrm{C}^{\mathrm{R}}$ & $\mathrm{C}^{\mathrm{R}}$ & $\mathrm{C}^{\mathrm{R}}$ \\
\hline & Canada & Japan & United Kingdom & Canada & Japan & United Kingdom & Canada & Japan & United Kingdom \\
\hline $\mathrm{L}^{\mathrm{R}}$ Canada & 1.000 & & & & & & & & \\
\hline $\mathrm{L}^{\mathrm{R}} \mathrm{Japan}$ & 0.588 & 1.000 & & & & & & & \\
\hline $\mathrm{L}^{\mathrm{R}}$ United Kingdom & 0.714 & 0.566 & 1.000 & & & & & & \\
\hline $\mathrm{S}^{\mathrm{R}}$ Canada & -0.080 & -0.021 & 0.223 & 1.000 & & & & & \\
\hline $\mathrm{S}^{\mathrm{R}}$ Japan & 0.046 & -0.070 & 0.149 & 0.624 & 1.000 & & & & \\
\hline $\mathrm{S}^{\mathrm{R}}$ United Kingdom & -0.180 & -0.153 & -0.225 & 0.639 & 0.664 & 1.000 & & & \\
\hline $\mathrm{C}^{\mathrm{R}}$ Canada & -0.586 & -0.159 & -0.261 & 0.079 & 0.113 & 0.084 & 1.000 & & \\
\hline $\mathrm{C}^{\mathrm{R}}$ Japan & -0.110 & -0.265 & -0.069 & 0.399 & 0.559 & 0.509 & 0.330 & 1.000 & \\
\hline $\mathrm{C}^{\mathrm{R}} \mathrm{UK}$ & -0.412 & -0.122 & -0.689 & -0.027 & -0.027 & 0.339 & 0.361 & 0.255 & 1.000 \\
\hline
\end{tabular}

Table 2.-Surveyed Forecasts and Yield Curve Factors

\begin{tabular}{ccccc}
\hline \hline & $m=3$ & $m=6$ & $m=9$ & $m=12$ \\
\hline$E_{t} \Delta y_{t+m}=\alpha_{S m}+\beta_{S m} S_{t}+u_{S m t}$ & 0.016 & -0.073 & $-0.083^{*}$ & $-0.192^{*}$ \\
$\beta_{S m}$ & $(0.065)$ & $(0.048)$ & $(0.034)$ & $(0.038)$ \\
Number of observations & 80 & 80 & 80 & 80 \\
Adjusted $R^{2}$ & -0.012 & 0.017 & 0.059 & 0.235 \\
$A_{t+m}=\gamma_{S m}+\delta_{S m} S_{t}+v_{S m t}$ & & & & \\
$\delta_{S m}$ & -0.352 & $1.078^{*}$ & $1.830^{*}$ & $1.950^{*}$ \\
& $(0.857)$ & $(0.526)$ & $(0.335)$ & $(0.344)$ \\
Number of observations & 80 & 80 & 80 & 80 \\
Adjusted $R^{2}$ & -0.011 & 0.039 & 0.267 & 0.283 \\
$E_{t} \pi_{t+m}=\alpha_{L m}+\beta_{L m} L_{t}+u_{L m t} t$ & & & \\
$\beta_{L m}$ & $0.458 *$ & $0.462^{*}$ & $0.468 *$ & $0.482^{*}$ \\
Number of observations & $(0.044)$ & $(0.039)$ & $(0.037)$ & $(0.037)$ \\
Adjusted $R^{2}$ & 0.579 & 0.638 & 0.663 & 0.684 \\
\hline
\end{tabular}

We use quarterly data from the Survey of Professional Forecasters maintained by the Federal Reserve Bank of Philadelphia. The factors are the quarterly average of the monthly data (though we obtain similar results when we use the first month of each quarter instead). *Indicates significance level below $10 \%$.

Index - a measure of the market's perceived probability of real GDP decline $k$ quarters later-with the current slope factor. Using data from 1985Q3 to 2005Q2, we run the following three sets of regressions, in accordance with the discussion in section II.B and Appendix A1, to evaluate the information embodied in the slope and level factors $S_{t}$ and $L_{t} \cdot{ }^{28}$

$$
\begin{aligned}
& E_{t} \Delta y_{t+m}=\alpha_{S m}+\beta_{S m} S_{t}+\beta_{y m} \Delta y_{t}+u_{S m t}, \\
& A_{t+m}=\gamma_{S m}+\delta_{S m} S_{t}+\delta_{y m} \Delta y_{t}+v_{S m t},
\end{aligned}
$$

${ }^{28}$ Additional results using all three factors are in the online appendix.

$$
\begin{aligned}
E_{t} \pi_{t+m}= & \alpha_{L m}+\beta_{L m} L_{t}+\beta_{\pi m} \pi_{t}+u_{L m t}, \\
& \text { for } \mathrm{m}=3,6,9, \text { and } 12 .
\end{aligned}
$$

Here $E \Delta y_{t+m}$ denotes real GDP growth forecast, $E \pi_{t+m}$ denotes the CPI inflation forecast, and $A_{t+m}$ is the Anxious Index for horizon $m$-month ahead. The first two regressions test whether the current slope reflects expected real GDP dynamics, and the third checks whether the level factor is correlated with expected future inflation. Since our main argument is that the factors can capture market expectations about the dynamics of future fundamentals beyond the currently observed fundamentals, we include them as additional regressors.

Table 2 shows that indeed, a larger slope factor (flatter slope) corresponds to lower expected output three quarters to a year ahead, as well as higher perceived probability of an economic downturn over the six-month to one-year horizons. A larger level factor consistently maps to higher expected inflation across all future horizons. These results are robust to the inclusion of the current fundamentals as well (results available on request).

\section{Estimation Specifications}

To see if the relative factors predict exchange rate changes and excess currency returns in sample, we run the following two main regressions, each for horizons $m=3,6$, 12,18 , and 24 , and also $m=1$ for equation (17): ${ }^{29}$

\footnotetext{
${ }^{29}$ Since one-month yield data are not available, we do not have excess
} return data to run equation (18). 
Table 3.-Predicting the Canadian-U.S. Exchange Rate and Excess Returns

\begin{tabular}{|c|c|c|c|c|c|c|}
\hline & $m=1$ & $m=3$ & $m=6$ & $m=12$ & $m=18$ & $m=24$ \\
\hline \multicolumn{7}{|c|}{ A. Exchange Rate Regressions: $\Delta s_{t+m}=\beta_{m, 0}+\beta_{m, 1} L_{t}^{R}+\beta_{m, 2} S_{t}^{R}+\beta_{m, 3} C_{t}^{R}+u_{t+m}$} \\
\hline $\mathrm{L}^{\mathrm{R}}$ & $-3.740 *$ & $-2.991 *$ & -1.957 & -1.646 & -1.418 & -0.915 \\
\hline$t / \sqrt{m}$ & -2.517 & -1.924 & -1.264 & -1.008 & -0.802 & -0.471 \\
\hline $\mathrm{S}^{\mathrm{R}}$ & -0.657 & -0.518 & -0.470 & -0.427 & -0.302 & -0.161 \\
\hline$t / \sqrt{m}$ & -1.361 & -0.775 & -0.709 & -0.613 & -0.402 & -0.195 \\
\hline $\mathrm{C}^{\mathrm{R}}$ & $-1.041 *$ & -0.923 & -0.692 & -0.524 & -0.564 & -0.492 \\
\hline$t / \sqrt{m}$ & -1.952 & -1.576 & -1.183 & -0.849 & -0.844 & -0.671 \\
\hline Number of observations & 239 & 237 & 234 & 228 & 222 & 216 \\
\hline \multicolumn{7}{|c|}{ B. Excess Currency Return Regressions: $i_{t}^{m *}-i_{t}^{m}+\Delta s_{t+m}=\gamma_{m, 0}+\gamma_{m, 1} L_{t}^{R}+\gamma_{m, 2} S_{t}^{R}+\gamma_{m, 3} C_{t}^{R}+v_{t+m}$} \\
\hline $\mathrm{L}^{\mathrm{R}}$ & & $-4.157 *$ & $-2.597 *$ & -2.646 & -2.493 & -1.933 \\
\hline$t / \sqrt{m}$ & & -2.651 & -1.657 & -1.611 & -1.419 & -1.002 \\
\hline$S^{R^{v}}$ & & $-1.326^{*}$ & $-1.323^{*}$ & $-1.158^{*}$ & -0.892 & -0.665 \\
\hline$t / \sqrt{m}$ & & -1.946 & -1.956 & -1.652 & -1.193 & -0.813 \\
\hline $\mathrm{C}^{\mathrm{R}}$ & & $-1.096^{*}$ & -0.754 & -0.750 & -0.884 & -0.784 \\
\hline$t / \sqrt{m}$ & & -1.805 & -1.279 & -1.207 & -1.332 & -1.078 \\
\hline Number of observations & & 233 & 224 & 228 & 222 & 216 \\
\hline
\end{tabular}

$$
\begin{aligned}
\Delta s_{t+m}= & \beta_{m, 0}+\beta_{m, 1} L_{t}^{R}+\beta_{m, 2} S_{t}^{R}+\beta_{m, 3} C_{t}^{R} \\
& +u_{t+m}, \\
r x_{t+m}= & \gamma_{m, 0}+\gamma_{m, 1} L_{t}^{R}+\gamma_{m, 2} S_{t}^{R}+\gamma_{m, 3} C_{t}^{R}+v_{t+m} .
\end{aligned}
$$

We note that for the United Kingdom, the relationship between the two dependent variables and the relative factors during the exchange rate mechanism (ERM) crisis differs significantly from the rest of the sample. ${ }^{30}$ So in our analysis, we drop the period October 1990 to September 1992, when the crisis was in effect, from the regressions for the United Kingdom.

It is well known that longer-horizon predictive analyses are prone to inference bias from using overlapping data. When the horizon for exchange rate change or excess currency return is more than one month, our left-hand-side variable overlaps across observations, and $u_{t+m}$ or $v_{t+m}$ in equations (17) and (18) will be a moving-average process of order $m-1$. Statistics such as the standard errors will be biased. One common solution is to use the Newey-West standard errors. However, the Newey-West adjustment suffers from serious size distortion (it rejects too often) when the sample size is small and the regressors are persistent. We address the problem using two alternative methods. The first method uses critical values constructed from Monte Carlo simulations (discussed in the online appendix). For the rest of the paper, we correct the long-horizon bias using the rescaled $t$ statistic suggested by Moon, Rubia, and Valkanov (2004) and Valkanov (2003), as it delivers more conservative inferences than the Monte Carlo results. As discussed in Appendix A1, Moon et al. (2004) propose to rescale standard $t$-statistics by $1 / \sqrt{m}$ and show that this rescaled $t$-statistic is approximately standard normal, provided that the regressor $x_{t}$ is highly persistent. When the regressor is not a near-integrated process, however, the adjusted $t$-statistic tends to

\footnotetext{
${ }^{30}$ We run equations (17) and (18) with the relative factors and their interaction with an ERM dummy and find significant results on the interaction terms. Figure $1 \mathrm{C}$ also shows the large jumps in the U.K. pound during this period.
}

underreject the null. Since the unit root null is rejected for most of our factors, we note that the predictive power of the factors may actually be stronger than implied by the results we present in tables 3 to $5^{31}$

\section{Main Results}

\section{A. Predictive Regressions}

Our main exchange rate predictive results based on equation (17) are presented in panel A of tables 3 to 5, with the corresponding results for excess returns, equation (18), in panel B. As a robustness check, we use the first month of each quarter and each half-year to construct a three-month and a six-month sample with no data overlap. We report the findings using the nonoverlapping data in table 6 .

For Canada, the relative factors do not seem to predict exchange rate movements beyond six months (panel $\mathrm{A}$ in tables 3 and 6), but they work better for excess returns (panel B in tables 3 and 6). The level and slope factors are statistically important in predicting excess returns up to a year, with quantitatively significant effect. For example, a 1 percentage point increase in the relative level factor (for example, a lower expected inflation in Canada) predicts more than a $4 \%$ annualized drop in the excess return of the Canadian dollar over the subsequent three months. Results based on nonoverlapping data reveal the same pattern: the three-month and six-month adjusted $R^{2}$ statistics for exchange rate change are only 0.03 and 0.01 , while for excess returns, they are 0.11 and 0.16 , with all three factors contributing at times. We note that the Canadian-U.S. results appear to be the weakest among the currency pairs

\footnotetext{
${ }^{31}$ We note that even though our estimations involve first running the Nelson-Siegel regressions, Pagan (1984)'s "estimated regressors" issue does not apply here. We are not trying to make inference on any true latent factors that are unobservable. Rather, the Nelson-Siegel factors we extract are merely used to summarize information in the yield curves, so whatever levels, slopes, or curvatures we obtain from the first stage are precisely the ones we want.
} 
Table 4.-Predicting the Japanese-U.S. Exchange Rate and Excess Returns

\begin{tabular}{|c|c|c|c|c|c|c|}
\hline & $m=1$ & $m=3$ & $m=6$ & $m=12$ & $m=18$ & $m=24$ \\
\hline \multicolumn{7}{|c|}{ A. Exchange Rate Regressions: $\Delta s_{t+m}=\beta_{m, 0}+\beta_{m, 1} L_{t}^{R}+\beta_{m, 2} S_{t}^{R}+\beta_{m, 3} C_{t}^{R}+u_{t+m}$} \\
\hline $\mathrm{L}^{\mathrm{R}}$ & -1.750 & -0.611 & -0.263 & -1.792 & -2.030 & -1.429 \\
\hline$t / \sqrt{m}$ & -0.566 & -0.203 & -0.090 & -0.731 & -0.815 & -0.602 \\
\hline$S^{R^{v}}$ & $-3.417 *$ & $-3.556^{*}$ & $-3.641^{*}$ & $-2.984 *$ & $-2.401 *$ & -2.193 \\
\hline$t / \sqrt{m}$ & -1.921 & -2.089 & -2.199 & -2.152 & -1.690 & -1.614 \\
\hline $\mathrm{C}^{\mathrm{R}}$ & -0.273 & 0.253 & 0.154 & -0.352 & -0.676 & -0.704 \\
\hline$t / \sqrt{m}$ & -0.227 & 0.202 & 0.126 & -0.344 & -0.647 & -0.707 \\
\hline Number of observations & 239 & 237 & 234 & 228 & 222 & 216 \\
\hline \multicolumn{7}{|c|}{ B. Excess Currency Return Regressions: $i_{t}^{m *}-i_{t}^{m}+\Delta s_{t+m}=\gamma_{m, 0}+\gamma_{m, 1} L_{t}^{R}+\gamma_{m, 2} S_{t}^{R}+\gamma_{m, 3} C_{t}^{R}+v_{t+m}$} \\
\hline $\mathrm{L}^{\mathrm{R}}$ & & -1.545 & -1.470 & -2.767 & -3.045 & -2.453 \\
\hline$t / \sqrt{m}$ & & -0.509 & -0.502 & -1.127 & -1.220 & -1.031 \\
\hline $\mathrm{S}^{\mathrm{R}}$ & & $-4.519 *$ & $-4.631 *$ & $-3.713 *$ & $-3.001 *$ & $-2.715^{*}$ \\
\hline$t / \sqrt{m}$ & & -2.609 & -2.768 & -2.672 & -2.108 & -1.993 \\
\hline $\mathrm{C}^{\mathrm{R}}$ & & 0.314 & 0.016 & -0.582 & -0.949 & -0.992 \\
\hline$t / \sqrt{m}$ & & 0.242 & 0.013 & -0.567 & -0.907 & -0.992 \\
\hline Number of observations & & 233 & 228 & 228 & 222 & 216 \\
\hline
\end{tabular}

The exchange rate $s$ is $\log (\mathrm{USD} / \mathrm{JPY})$. The row $t / \sqrt{m}$ reports the rescaled $t$-statistics for the estimates (see text for details). Estimates for the constant term are omitted. *Indicates significance level below $10 \%$.

Table 5.-PRedicting the U.K.-U.S. Exchange Rate and Excess Returns

\begin{tabular}{|c|c|c|c|c|c|c|}
\hline & $m=1$ & $m=3$ & $m=6$ & $m=12$ & $m=18$ & $m=24$ \\
\hline \multicolumn{7}{|c|}{ A. Exchange Rate Regressions: $\Delta s_{t+m}=\beta_{m, 0}+\beta_{m, 1} L_{t}^{R}+\beta_{m, 2} S_{t}^{R}+\beta_{m, 3} C_{t}^{R}+u_{t+m}$} \\
\hline $\mathrm{L}^{\mathrm{R}}$ & $-2.970 *$ & $-4.037 *$ & $-3.210 *$ & $-2.664 *$ & -2.129 & -1.585 \\
\hline$t / \sqrt{m}$ & -1.761 & -2.382 & -2.119 & -1.853 & -1.489 & -1.142 \\
\hline $\mathrm{S}^{\mathrm{R}}$ & $-2.509 *$ & $-2.341 *$ & $-1.752 *$ & -1.170 & -0.943 & -0.777 \\
\hline$t / \sqrt{m}$ & -2.037 & -2.080 & -1.746 & -1.236 & -0.999 & -0.840 \\
\hline $\mathrm{C}^{\mathrm{R}}$ & -0.504 & $-1.221 *$ & $-1.164 *$ & $-0.934 *$ & -0.743 & -0.451 \\
\hline$t / \sqrt{m}$ & -0.745 & -1.962 & -2.061 & -1.692 & -1.327 & -0.820 \\
\hline Number of observations & 215 & 213 & 210 & 204 & 198 & 192 \\
\hline \multicolumn{7}{|c|}{ B. Excess Currency Return Regressions: $i_{t}^{m *}-i_{t}^{m}+\Delta s_{t+m}=\gamma_{m, 0}+\gamma_{m, 1} L_{t}^{R}+\gamma_{m, 2} S_{t}^{R}+\gamma_{m, 3} C_{t}^{R}+v_{t+m}$} \\
\hline $\mathrm{L}^{\mathrm{R}}$ & & $-4.991 *$ & $-4.450 *$ & $-3.814 *$ & $-3.197 *$ & $-2.595 *$ \\
\hline$t / \sqrt{m}$ & & -2.940 & -2.451 & -2.586 & -2.222 & -1.867 \\
\hline & & $-3.219 *$ & $-2.860^{*}$ & $-2.014 *$ & $-1.590 *$ & -1.359 \\
\hline$t / \sqrt{m}$ & & -2.861 & -2.178 & -2.051 & -1.675 & -1.467 \\
\hline $\mathrm{C}^{\mathrm{R}}$ & & $-1.247 *$ & $-1.207 *$ & $-1.143^{*}$ & $-1.038^{*}$ & -0.779 \\
\hline$t / \sqrt{m}$ & & -1.965 & -1.804 & -2.041 & -1.841 & -1.416 \\
\hline Number of observations & & 209 & 159 & 195 & 198 & 192 \\
\hline
\end{tabular}

The exchange rate $s$ is $\log (\mathrm{USD} / \mathrm{GBP})$. The row $t / \sqrt{m}$ reports the rescaled $t$-statistics for the estimates (see text for details). Estimates for the constant term are omitted. ${ }^{*}$ Indicates significance level below $10 \%$.

TABle 6.-Regressions Using Nonoverlapping Data

\begin{tabular}{|c|c|c|c|c|c|c|}
\hline & \multicolumn{2}{|c|}{ Canada } & \multicolumn{2}{|c|}{ Japan } & \multicolumn{2}{|c|}{ United Kingdom } \\
\hline & $m=3$ & $m=6$ & $m=3$ & $m=6$ & $m=3$ & $m=6$ \\
\hline \multicolumn{7}{|c|}{ A. Exchange Rate Regressions } \\
\hline $\mathrm{L}^{\mathrm{R}}$ & $\begin{array}{c}-3.422 * \\
(1.417)\end{array}$ & $\begin{array}{c}-1.734 \\
(1.431)\end{array}$ & $\begin{array}{c}-1.651 \\
(2.926)\end{array}$ & $\begin{array}{c}0.786 \\
(2.968)\end{array}$ & $\begin{array}{c}-5.213^{*} \\
(1.865)\end{array}$ & $\begin{array}{c}-3.054^{*} \\
(1.115)\end{array}$ \\
\hline $\mathrm{S}^{\mathrm{R}}$ & $\begin{array}{c}-0.499 \\
(0.521)\end{array}$ & $\begin{array}{c}-0.705 * \\
(0.415)\end{array}$ & $\begin{array}{l}-2.612 \\
(1.740)\end{array}$ & $\begin{array}{l}-2.677 \\
(1.948)\end{array}$ & $\begin{array}{c}-1.660 \\
(1.160)\end{array}$ & $\begin{array}{r}-1.775^{*} \\
(0.762)\end{array}$ \\
\hline $\mathrm{C}^{\mathrm{R}}$ & $\begin{array}{r}-0.956^{*} \\
(0.530)\end{array}$ & $\begin{array}{r}-0.739 \\
(0.450)\end{array}$ & $\begin{array}{c}-0.499 \\
(1.363)\end{array}$ & $\begin{array}{c}-0.457 \\
(1.517)\end{array}$ & $\begin{array}{r}-1.773 * \\
(0.734)\end{array}$ & $\begin{array}{r}-1.109 * \\
(0.448)\end{array}$ \\
\hline $\begin{array}{l}\text { Number of observations } \\
\text { Adjusted } R^{2}\end{array}$ & $\begin{array}{c}79 \\
0.031\end{array}$ & $\begin{array}{c}39 \\
0.009\end{array}$ & $\begin{array}{c}79 \\
0.017\end{array}$ & $\begin{array}{c}39 \\
0.037\end{array}$ & $\begin{array}{c}71 \\
0.108\end{array}$ & $\begin{array}{c}35 \\
0.200\end{array}$ \\
\hline \multicolumn{7}{|c|}{ B. Excess Currency Return Regressions } \\
\hline $\mathrm{L}^{\mathrm{R}}$ & $\begin{array}{c}-4.590 * \\
(1.406)\end{array}$ & $\begin{array}{r}-2.647 * \\
(1.416)\end{array}$ & $\begin{array}{l}-2.722 \\
(2.918)\end{array}$ & $\begin{array}{l}-0.175 \\
(2.978)\end{array}$ & $\begin{array}{r}-6.153 * \\
(1.869)\end{array}$ & $\begin{array}{r}-3.914^{*} \\
(1.410)\end{array}$ \\
\hline$S^{R}$ & $\begin{array}{c}-1.362^{*} \\
(0.512)\end{array}$ & $\begin{array}{c}-1.547 * \\
(0.417)\end{array}$ & $\begin{array}{r}-3.512^{*} \\
(1.737)\end{array}$ & $\begin{array}{c}-3.510^{*} \\
(1.951)\end{array}$ & $\begin{array}{c}-2.424 * \\
(1.128)\end{array}$ & $\begin{array}{c}-3.223^{*} \\
(1.048)\end{array}$ \\
\hline $\mathrm{C}^{\mathrm{R}}$ & $\begin{array}{r}-1.117 * \\
(0.533)\end{array}$ & $\begin{array}{r}-0.846^{*} \\
(0.442)\end{array}$ & $\begin{array}{r}-0.578 \\
(1.359)\end{array}$ & $\begin{array}{c}-0.604 \\
(1.524)\end{array}$ & $\begin{array}{r}-1.904^{*} \\
(0.730)\end{array}$ & $\begin{array}{r}-0.899 * \\
(0.588)\end{array}$ \\
\hline Number of observations & 79 & 39 & 79 & 39 & 71 & 28 \\
\hline Adjusted $R^{2}$ & 0.105 & 0.157 & 0.057 & 0.102 & 0.162 & 0.271 \\
\hline
\end{tabular}

Newey-West standard errors are reported in the parentheses. We use the first month of a quarter and the first month of every half-year to construct nonoverlapping samples. Observations during the ERM period are dropped for the United Kingdom. *Indicates significance level below $10 \%$. 
we examined, with the predictability dissipating quickly after six months. Our conjecture is that this is mainly due to the Canadian dollar's commodity currency status, as discussed previously in the literature. ${ }^{32}$

For Japan, the relative slope factor plays both a statistically and an economically strong role in predicting the yen-dollar movements. As shown in table 4, panel A, a 1 percentage point increase in the relative slope factor (the Japanese yield curve becomes steeper relative to the U.S. one, reflecting, for example, stronger Japanese growth prospects) predicts a $3.6 \%$ annualized depreciation of the yen over the next three months. In panel B, the same $1 \%$ increase in the relative slope factor predicts a $4.5 \%$ drop in excess yen returns over the U.S. dollar in the three-month horizon. The same pattern can be observed over horizons up to two years. These results make intuitive sense: during periods in which the Japanese relative growth prospect is high (compared to the sample average), the yen should be strong and investors would demand less risk premium for holding yen. Subsequently, the yen depreciates toward its equilibrium value (sample average). Interestingly, we do not find statistically significant results for the other two relative factors.

For the United Kingdom, table 5 shows that all three Nelson-Siegel factors predict exchange rate changes and ex-post excess returns with quantitatively and statistically significant impact. A one percentage point increase in the relative level factor (the whole yield curve of the United States shifts up by one percentage point relative to that of the United Kingdom) predicts a $4 \%$ depreciation of the pound against the dollar and a 5\% drop in the excess sterling return over the subsequent quarter. The explanatory power of the relative factors for ex-post excess return in fact extends beyond two years (not shown). The nonoverlapping results in table 6 confirm the relative factors' importance. The three-month and six-month adjusted $R^{2}$ statistics for exchange rate change are 0.11 and 0.20 , and for excess return they are 0.16 and 0.27 . We note that these are high numbers; they contrast sharply with the view that exchange rates are disconnected from macrofundamentals.

Overall, we see that for all three currency pairs, the relative yield curve factors can play a quantitatively and statistically significant role in explaining future exchange rate movements over future intervals ranging from one month to two years. We also observe a consistent pattern across currency pairs: the effects of the factors, as captured by the size of the regression coefficients, tend to approach 0 as the forecast horizon increases. We view this as an indication that current information and expectations have a declining effect on the actual exchange rate realization further into the future; however, imprecision in the estimates and likely bias from noise in longer-horizon data prevent any conclusive state-

\footnotetext{
32 The Canadian dollar is known to respond chiefly to the world price of the country's primary commodity exports (see Chen \& Rogoff, 2003, for further discussion on commodity currencies) In addition, Krippner (2006) found that the failure of the UIP in the CAD/USD rate is associated with the cyclical component of Canadian interest rates.
}

ment. (We present parallel results based on more recent data covering January 1991 to May 2011 in the online appendix.)

\section{B. Comparison with Interest Differential Regressions}

Given our positive results, a natural question is how our factor model, using information contained in the full yield curves, compares to specifications using interest differentials of only one (for example, UIP) or two maturities (Frankel 1979). Below we present the discussion using the UIP regression as an example, though the logic applies to other cases as well.

The UIP puzzle originates from observing a negative and often significantly estimated coefficient $\beta$ in the following regression setup for $m$ in the one-year range:

$$
\Delta s_{t+m}=\alpha+\beta\left(i_{t}^{m}-i_{t}^{m *}\right)+\varepsilon_{t+m} .
$$

While it implies that exchange rate change is predictable by interest rate differentials, we note that this in-sample predictability is consistent with exchange rate disconnect, or Meese-Rogoff (1983) random walk results, as the explanatory power of interest differences is typically extremely small. ${ }^{33}$ How does our Nelson-Siegel (NS) factor approach relate to the UIP regression? Intuitively, our yield curve approach augments the $m$-period UIP regression with yield differences of all other maturities. Given the estimation problem associated with having many highly collinear regressors, the NS factors serve as a parsimonious way to reduce dimension, with the additional benefit of having well-established macroeconomic interpretations.

Mathematically, it is also easy to see that equation (19) is a constrained version of our factor model, equation (17). Substituting the formula for the relative Nelson-Siegel yield curve equation (10) into equation (19) and rearranging terms, the UIP regression takes the following form:

$$
\begin{aligned}
& \Delta s_{t+m}=\alpha+\beta L_{t}^{R}+\beta\left(\frac{1-\exp (-\lambda m)}{\lambda m}\right) S_{t}^{R} \\
& \quad+\beta\left(\frac{1-\exp (-\lambda m)}{\lambda m}-\exp (-\lambda m)\right) C_{t}^{R}+\varepsilon_{t+m} .
\end{aligned}
$$

This shows that the UIP regression is a constrained version of our model, equation (17), with the following two horizon (m)-dependent restrictions:

$$
\begin{aligned}
& \frac{\beta_{2, m}}{\beta_{1, m}}=\left(\frac{1-\exp (-\lambda m)}{\lambda m}\right), \\
& \frac{\beta_{3, m}}{\beta_{1, m}}=\left(\frac{1-\exp (-\lambda m)}{\lambda m}-\exp (-\lambda m)\right) .
\end{aligned}
$$

Since our model encompasses the UIP regression, we can formally test whether these restrictions are supported in the

\footnotetext{
${ }^{33}$ Fama (1984) reports an average $R^{2}$ of 0.01 for monthly data; see also Chinn (2006) and Chinn and Meredith (2004).
} 


\begin{tabular}{|c|c|c|c|c|c|c|}
\hline & \multicolumn{2}{|c|}{$m=3$} & \multicolumn{2}{|c|}{$m=6$} & \multicolumn{2}{|c|}{$m=9$} \\
\hline & Factors & UIP & Factors & UIP & Factors & UIP \\
\hline \multicolumn{7}{|c|}{$\begin{array}{c}\text { Factors: } \Delta s_{t+m}=\beta_{0}+\beta_{1} L_{t}^{R}+\beta_{2} S_{t}^{R}+\beta_{3} C_{t}^{R}+u_{t+m} \\
\text { UIP: } \Delta s_{t+m}=\alpha+\beta\left(i_{t}^{m}-i_{t}^{m *}\right)+\varepsilon_{t+m}\end{array}$} \\
\hline $\begin{array}{l}\text { Canada } \\
\text { Number of observations* }\end{array}$ & \multicolumn{2}{|c|}{233} & \multicolumn{2}{|l|}{0.04} & \multicolumn{2}{|c|}{229} \\
\hline $\begin{array}{l}\text { Japan } \\
\text { Number of observations }\end{array}$ & \multicolumn{2}{|c|}{233} & \multicolumn{2}{|c|}{228} & \multicolumn{2}{|c|}{230} \\
\hline $\begin{array}{l}\text { United Kingdom } \\
\text { Number of observations }\end{array}$ & \multicolumn{2}{|c|}{209} & \multicolumn{2}{|c|}{159} & \multicolumn{2}{|c|}{187} \\
\hline \multicolumn{7}{|c|}{$\begin{array}{l}\text { B. Controlling for Risks: Adding Long Rates in the UIP Regression: } \\
\qquad \Delta s_{t+m}=\alpha+\beta\left(i_{t}^{m}-i_{t}^{m *}\right)+\delta \rho_{t+m}^{F}+\varepsilon_{t+m}\end{array}$} \\
\hline & & with Long & & with Long & & with Long \\
\hline$m=3$ months & UIP & Rates & UIP & Rates & UIP & Rates \\
\hline$\alpha$ & $\begin{array}{r}-0.940 \\
(1.241)\end{array}$ & $\begin{array}{l}-3.471 \\
(1.397)\end{array}$ & $\begin{array}{l}10.192 \\
(3.171)\end{array}$ & $\begin{array}{c}-1.222 \\
(5.904)\end{array}$ & $\begin{array}{r}-3.497 \\
(2.344)\end{array}$ & $\begin{array}{c}-1.151 \\
(2.617)\end{array}$ \\
\hline$\beta$ & $\begin{array}{c}-1.009 * \\
(0.379)\end{array}$ & $\begin{array}{c}1.444 \\
(1.459)\end{array}$ & $\begin{array}{c}-2.610 * \\
(1.093)\end{array}$ & $\begin{array}{c}3.923 \\
(4.478)\end{array}$ & $\begin{array}{c}-2.721^{*} \\
(0.912)\end{array}$ & $\begin{array}{c}1.284 \\
(2.146)\end{array}$ \\
\hline$m=6$ months & & & & & & \\
\hline$\alpha$ & $\begin{array}{c}-0.088 \\
(1.007)\end{array}$ & $\begin{array}{l}-2.418 \\
(1.054)\end{array}$ & $\begin{array}{l}11.866 \\
(2.812)\end{array}$ & $\begin{array}{c}1.523 \\
(5.082)\end{array}$ & $\begin{array}{c}-1.175 \\
(1.935)\end{array}$ & $\begin{array}{c}-0.834 \\
(1.771)\end{array}$ \\
\hline$\beta$ & $\begin{array}{c}-0.627^{*} \\
(0.341)\end{array}$ & $\begin{array}{l}1.643 \\
(1.121)\end{array}$ & $\begin{array}{c}-3.391^{*} \\
(0.911)\end{array}$ & $\begin{array}{c}-4.504 \\
(5.909)\end{array}$ & $\begin{array}{c}-2.452^{*} \\
(0.924)\end{array}$ & $\begin{array}{l}2.200 \\
(1.972)\end{array}$ \\
\hline$m=9$ months & & & & & & \\
\hline$\alpha$ & $\begin{array}{c}-0.306 \\
(0.861)\end{array}$ & $\begin{array}{c}-2.379 \\
(0.934)\end{array}$ & $\begin{array}{l}12.191 \\
(2.171)\end{array}$ & $\begin{array}{c}5.726 \\
(4.014)\end{array}$ & $\begin{array}{c}-1.039 \\
(1.444)\end{array}$ & $\begin{array}{c}-0.834 \\
(1.294)\end{array}$ \\
\hline$\beta$ & $\begin{array}{c}-0.750 * \\
(0.389)\end{array}$ & $\begin{array}{c}2.324 * \\
(1.357)\end{array}$ & $\begin{array}{c}-3.319 * \\
(0.712)\end{array}$ & $\begin{array}{c}-6.772 \\
(5.881)\end{array}$ & $\begin{array}{c}-2.257^{*} \\
(0.699)\end{array}$ & $\begin{array}{l}5.868 * \\
(2.998)\end{array}$ \\
\hline
\end{tabular}

In panel A, due to the missing observations in short maturity yields, the sample for the factor model is adjusted to match that of the UIP regressions.

The UIP regressions in panel B exclude the risk premium term $\delta \rho_{t+m}^{F}$. One- and five-year interest differentials are added as a proxy for $\rho_{t+m}^{F}$ in the "with Long Rates" regressions. *Indicates significance level below $10 \%$.

data and whether the flexibility offered by the factor models is useful. We discuss this more fully over the next section and the online appendix, but first report in table 7A adjusted $R^{2}$ comparisons between the two models using the full sample period. We see that in terms of in-sample fit, the factors offer marginal improvements up to 0.07 .

\section{Model Comparisons over Subsamples}

To supplement the above results, we further compare the factor model and the interest differential model over subsample periods using a rolling window of five years. This exercise is motivated by the common finding in the literature that the additional predictive or forecast content in the more general specifications can be episodic (see Stock \& Watson, 2008). That is, there are periods where the additional information in the more comprehensive models offers significant explanatory power, but at other times, these models perform similarly to the more restricted specifications. We illustrate this point by looking at three sets of tests using a five-year rolling window over the full sample period. First, we test for the validity of the restrictions a the interest-differential model imposed on the NelsonSiegel factors, as derived in equation (21), for $m=3,6$, and 12 months; results are plotted in figures $2 \mathrm{~A}$ to $2 \mathrm{C}$. The $10 \%$ critical value is generated by Monte Carlo simulations to account for small sample bias and autocorrelations in the data (see Appendix A3). In all cases, we see clearly that the
$F$-tests indicate rejections of the UIP restrictions in favor of the factor model (when the $F$-statistic is above the $10 \%$ critical value). For example, the 1990s seem to be a period in which that the factor model is favored in Canada.

Next, we plot and compare the recursively constructed adjusted $R^{2}$ s for the interest differential model and the more general factor model, again using a five-year rolling window. ${ }^{34}$ Figure 3B shows that for Japan, the interest-differential model has a better fit, though the differences are small. This result may be related to our earlier findings that only the slope factors are found to be significant for Japan, suggesting that the flexibility of the Nelson-Siegel curve offers little value (but adds estimation costs). For Canada and the United Kingdom (figures 3A and 3C), on the other hand, we see subperiods where the Nelson-Siegel factor model provides large improvements over the single-maturity interest differential model.

\section{Discussion}

\section{A. Interpretation}

Although we do not explicitly test for any specific macroeconomic models discussed in section IIA, our positive results nevertheless have intuitive economic interpretations.

\footnotetext{
${ }^{34}$ To adjust for bias due to overlapping observations, the adjusted- $R^{2}$ statistics are constructed using Monte Carlo simulations (see Appendix A3).
} 

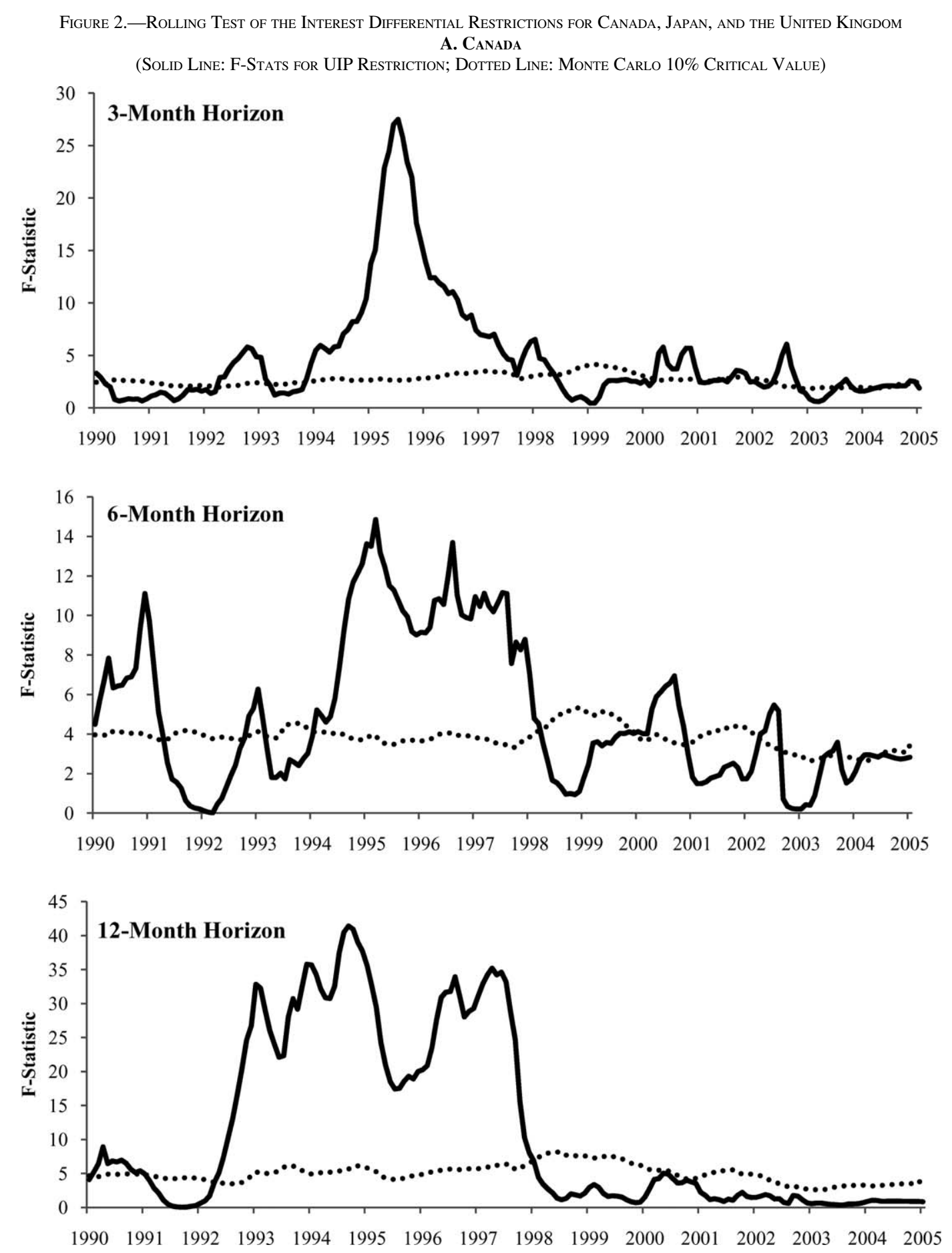

As discussed in section IIB, the yield curve literature shows that when a country's yield curve is flat or its level high, the market expects a forthcoming economic downturn or rising inflation in that country, respectively. Keeping everything else equal, our results show that in these situations, its currency is less desirable and faces depreciation pressure, in accordance with the present value relation, as in equation (8). Subsequently, its currency will appreciate and recover toward its long-run equilibrium level. Our finding that there is a declining impact of yield curve information on currency movements further into the horizon supports this view and suggests that movements in market expectations tend to be transitory.

Assuming away systematic market expectation errors, excess foreign currency return can be considered the risk premium associated with holding this currency (see equation [12]). Our results show that the currency risk premium, $\rho^{F}$, correlates strongly with the relative yield curve factors. When market expectations point to more output decline (flatter relative slope) or higher future inflation (higher rela- 
Figure 2.-(COnTINUEd)

B. JAPAN

(Solid Line: F-Stats for UiP Restriction; Dotted Line: Monte Carlo 10\% Critical Value)
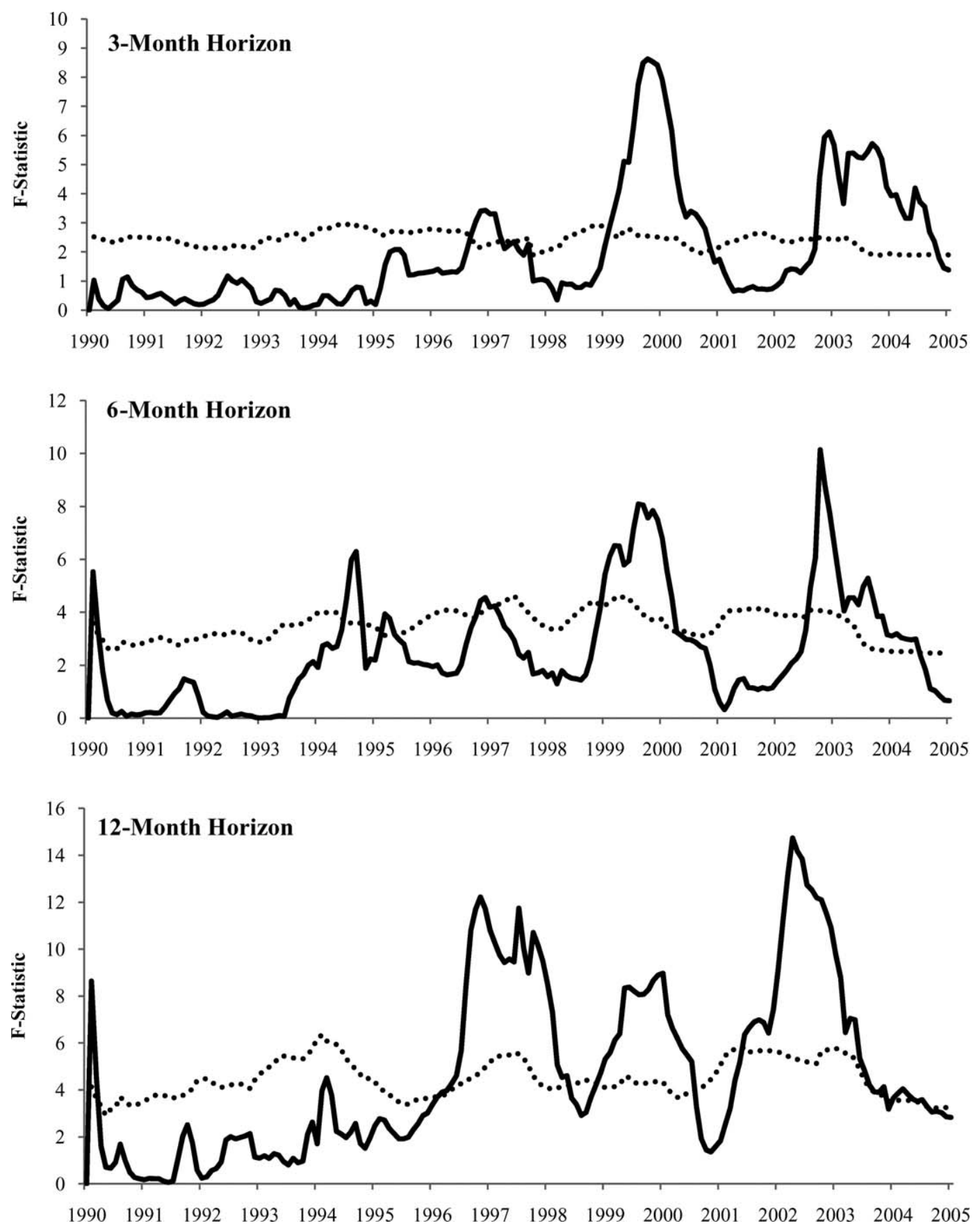

tive level) in a foreign country, we see a correspondingly high foreign currency risk premium. ${ }^{35}$ This pattern makes intuitive sense. For example, consider the case of a high relative level factor abroad, signaling a higher expected inflation there. During periods when inflation is high, the purchasing power of nominal currency declines, and its relative value (exchange rate) weakens according to the pre-

\footnotetext{
${ }^{35}$ In the notation of equation (18), this means when either $S^{R}$ or $L^{R}$ is low, excess return or $\rho^{F}$ is high.
}

sent value model. This means that both the real and relative returns of foreign currency are low. To the extent that inflation and consumption growth are negatively correlated (as documented in the literature), we see a negative covariance between foreign currency returns and the marginal utility of consumption. ${ }^{36}$ Foreign currency is thus risky - a bad hedge

\footnotetext{
${ }^{36}$ Piazzesi and Schneider (2006) use postwar U.S. data and find inflation to be negatively correlated with current, past, and future consumption growth. Inflation risk therefore explains the positive (yield) term premiums.
} 

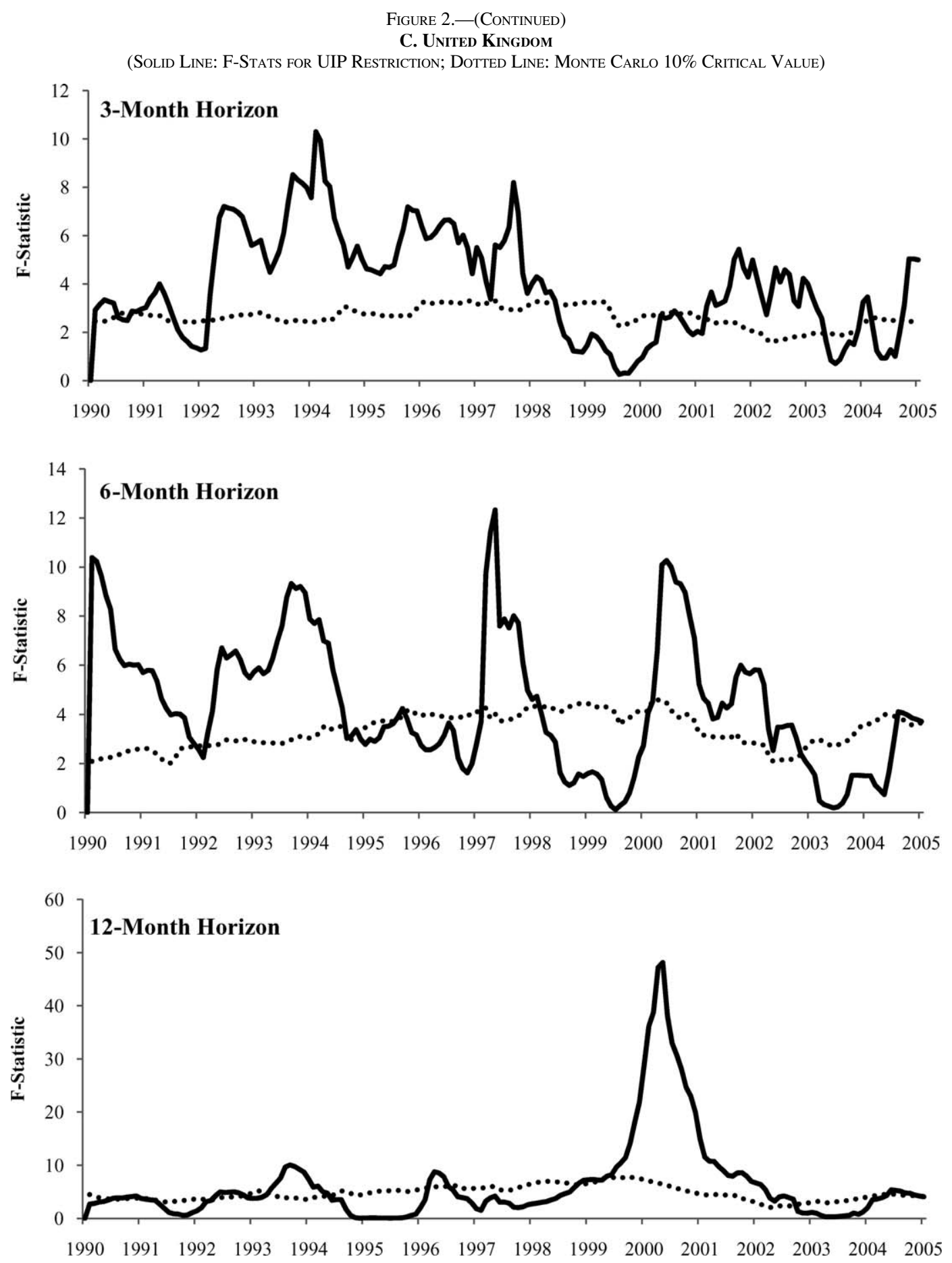

The solid line plots the $F$-statistic for the null hypothesis that the restriction imposed by the UIP on the N-S factors is correct. The dotted line is the Monte Carlo $10 \%$ critical value, accounting for small sample bias and persistence of the data. For more details, see the appendix.

for inflation risk - so $\rho^{F}$ is high. A similar argument can be made about the slope factor, which reflects business cycle or output growth dynamics. When the relative slope is flatter abroad, agents expect low output there and a weaker foreign currency. The low payoff from the foreign currency in states of nature in which output and consumption are low (marginal utility high) makes it a bad hedge and a risky asset, which must offer a risk premium. Although our paper does not formally prove any structural mechanism, our robust results are in line with basic economic intuition.

\section{B. An Explanation of the UIP Puzzle}

Our finding that the risk premium increases with a higher level factor or a flatter slope also offers a viable explanation to the UIP puzzle. In the context of equation (12), resolving 
Figure 3.-Recursive Adjusted $R^{2}$ with a Five-Year Rolling Window (CAnada)

A. Canada

(Solid Line: Factor Model; Dotted Line: InTERest Differential Model)
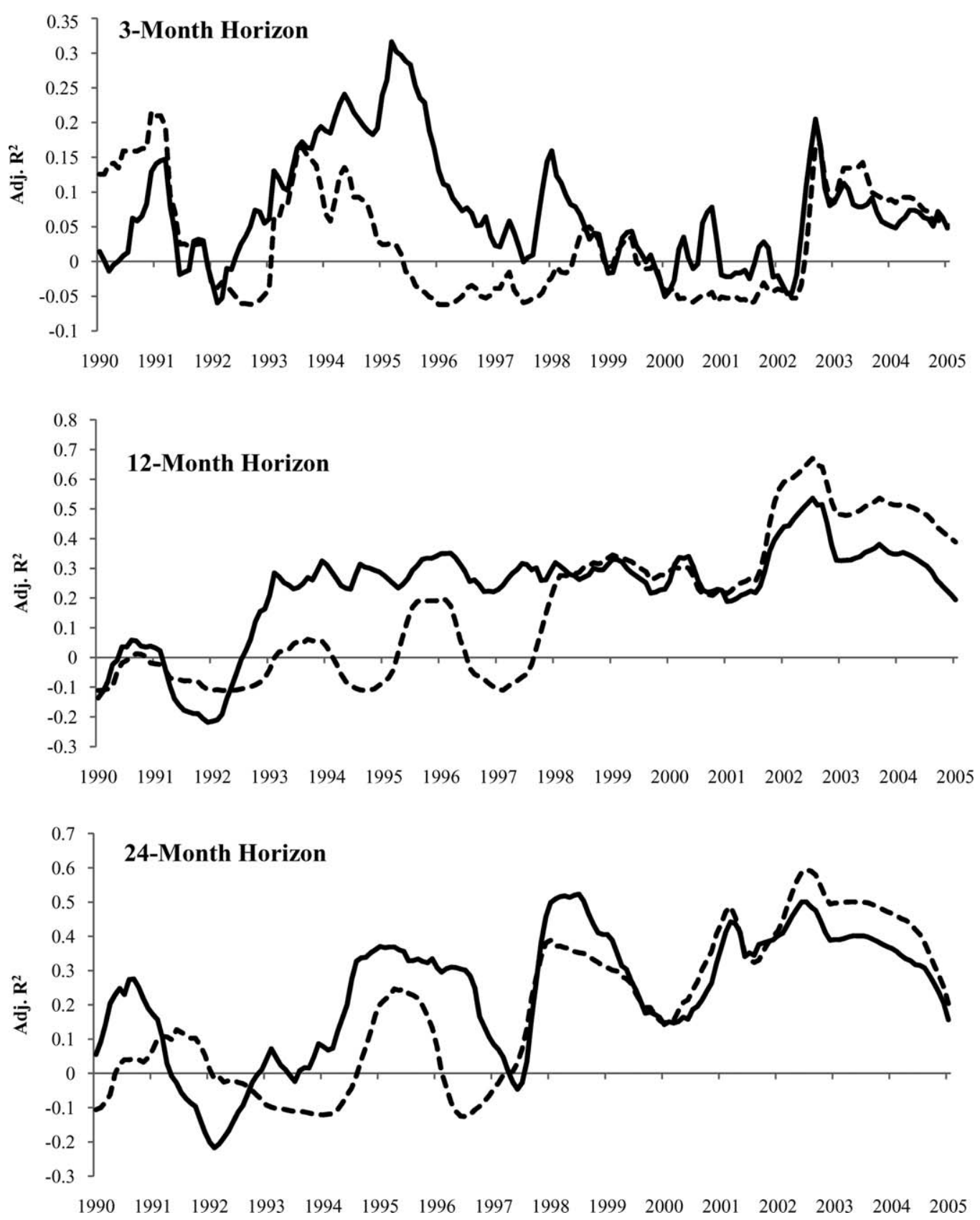

the UIP puzzle means explaining why a rise in $i_{t}^{m *}$ or a drop in $i_{t}^{m}$ can lead to an increase in $\Delta s_{t+m}$ (for small $m$ ). Let us consider an increase in the foreign short-term interest rate $i^{*}$. Crudely speaking, its impact on the shape of the foreign yield curve would entail either flattening it (if the long rates do not respond) or raising the whole curve (if the longer maturity rates go up as well). ${ }^{37}$ Assuming the home yield curve stays fixed, this corresponds to the scenario we dis-

\footnotetext{
${ }^{37}$ This also implies that the short rate differences and the relative factors should be positively correlated, which we do observe in our data. We also find the correlation to be declining with yields of longer maturity.
}

cussed above and $\rho^{F}$ should rise. It is then easy to see from equation (12) that if the rise in $\rho^{F}$ is large enough, $\Delta s_{t+m}$ can indeed turn positive: foreign currency appreciates in response to a rise in foreign interest rate.

From an econometric perspective, this result points to an omitted-variable bias problem in the original UIP regression. By omitting the risk premium term $\rho^{F}$ that is negatively correlated with $\left(i_{t}^{m}-i_{t}^{m *}\right)$, the estimated coefficient for the interest differential term would be biased downward from 1 and might turn negative, resulting in the UIP puzzle. Indeed, we report in table $7 \mathrm{~B}$ the UIP coefficient estimates for horizons three, six, and nine months, both with and without the inclu- 

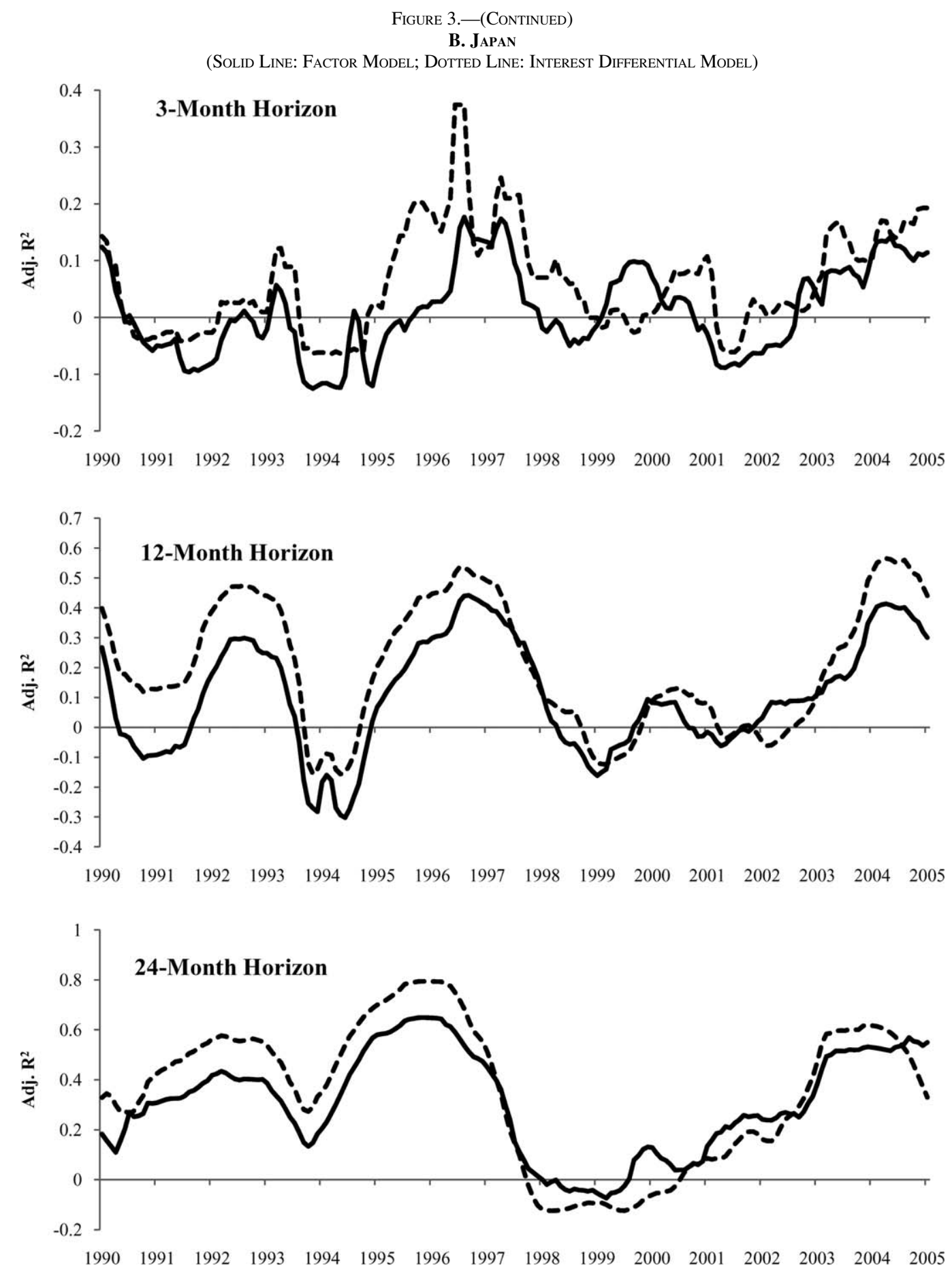

sion of two additional regressors - the one- and the five-year yield differentials - which we use to proxy $\rho^{F}{ }^{38}$ We observe a consistent pattern here. The slope coefficients $\beta$ are all significantly negative under the original UIP specification, confirming the puzzle. Once the omitted risk term (long bond

${ }^{38}$ As explained in section IV.B, the yield factors encompass any single maturity interest rate, so including the factors in the regression would lead to perfect collinearity. We thus use only two long-yield differences to proxy the omitted risk. yield differential) is included, these coefficients all either turn positive or become insignificantly different from 0 .

From a practical standpoint, our finding suggests that to predict currency return over a short horizon, one can do better than looking at just the interest differentials of the corresponding maturity (UIP). By looking at the rest of the yield curves of the two countries, one can obtain additional information on the relative risk that market participants perceive regarding the two currencies. If the country with the higher short rate has lower long-maturity yields relative to the 

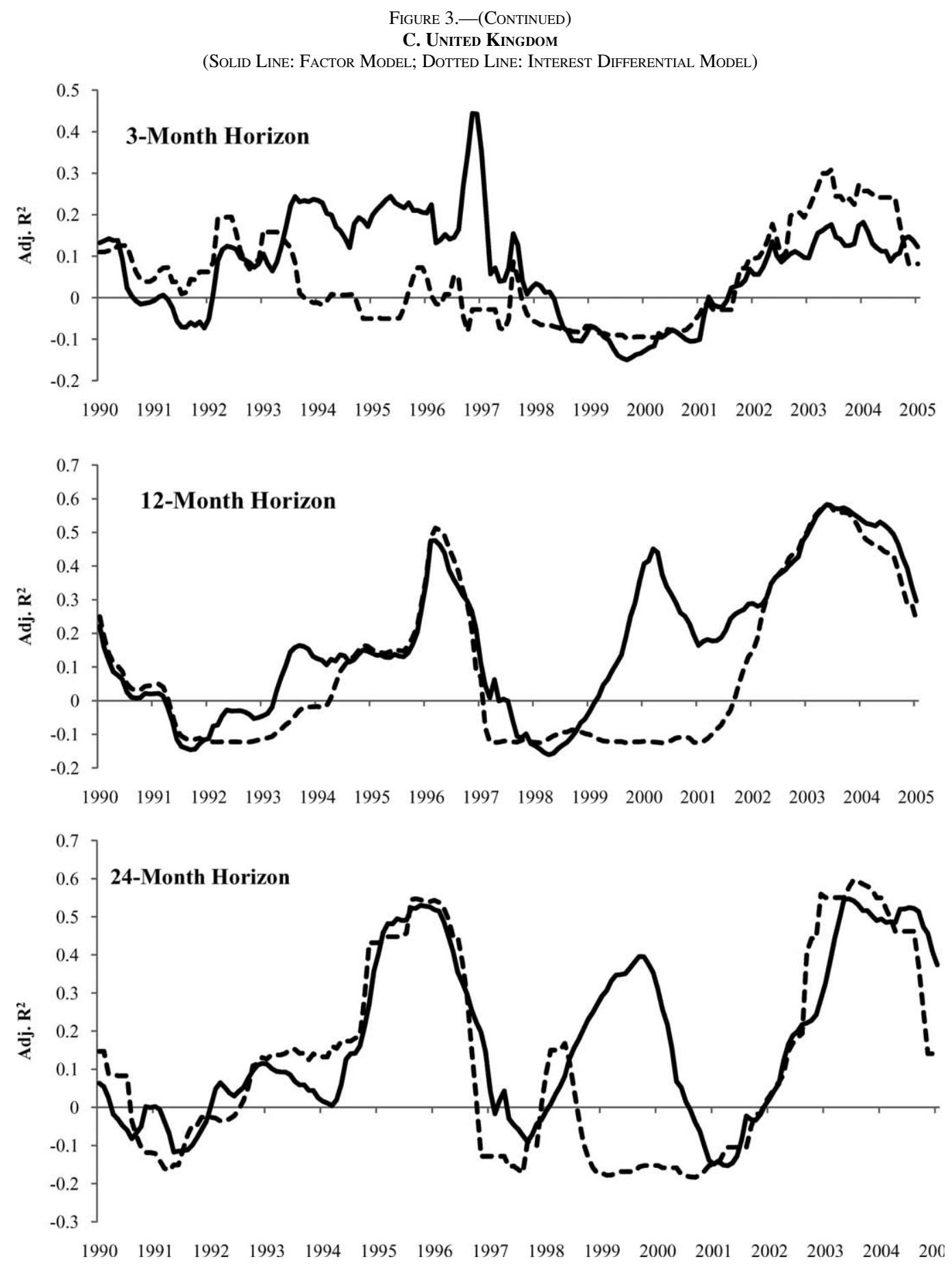

Recursive OLS is estimated using a 5-year rolling window. The solid line is the Adjusted $\mathrm{R}^{2}$ for the factor model in equation (17), and the dotted line is for the interest differential model in equation (19).

yields of the other country, its currency would tend to appreciate subsequently, as the market prices in a large risk premium to compensate for the unfavorable economic conditions anticipated for this country. Our results are also consistent with the longer-horizon UIP literature, where, for example, Chinn and Meredith (2004) find that the UIP holds better over horizons of five to ten years. We observe that the relative factors, embodying current expectations about future economic dynamics, have a declining impact on ex post risk premiums over longer horizons. This suggests that expectations and risk perceived at time $t$ for horizons further into the future tend to more neutral. As such, the long-horizon exchange rate movements are less affected by risk premium and should be more in line with basic fundamentals such as the UIP interest differentials.

\section{Conclusion}

We find that the Nelson-Siegel factors extracted from the relative yield curves between two countries can explain 
future exchange rate movements and excess currency returns. Unlike the exchange rate disconnect conclusion that has dominated the literature, our results provide support for the view that exchange rate movements are systematically related to expected future macroeconomic fundamentals in accordance with theoretical models that imply a present value relationship. The main insight here is that since market expectations may be too complicated to be captured by simple statistical models, we should look for such information in the data. Given that the term structure of interest rates has been found to embody market expectations of future macroeconomic dynamics, the present value exchange rate models can thus be tested without having to impose either structural or statistical assumptions on the expectation-formation process. Our findings support this approach: the difference between two countries' yield curves can predict the relative value of their currencies and risk premiums. Our results also, as a natural consequence, offer a simple and intuitive explanation for the UIP puzzle.

\section{REFERENCES}

Ang, Andrew, Monika Piazzesi, and Min Wei, "What Does the Yield Curve Tell us about GDP Growth?" Journal of Econometrics 131 (2006), 359-403.

Barr, David G., and John Y. Campbell, "Inflation, Real Interest Rates, and the Bond Market: A Study of UK Nominal and Index-Linked Government Bond Prices," Journal of Monetary Economics 39 (1997), 361-383.

Bekaert, Geert, Seonghoon Cho, and Antonio Moreno, "New-Keynesian Macroeconomics and the Term Structure," Journal of Money, Credit and Banking 42 (2010), 33-62.

Bekaert, Geert, Min Wei, and Yuhang Xing, "Uncovered Interest Rate Parity and the Term Structure," Journal of International Money and Finance 26 (2007), 1038-1069.

Boudoukh, J., M. P. Richardson, and R. F. Whitelaw, "The Information in Long-Maturity Forward Rates: Implications for Exchange Rates and the Forward Premium Anomaly," NBER working paper 11840 (2005).

Chen, Yu-chin, and Kenneth S. Rogoff, "Commodity Currencies," Journal of International Economics 60, (2003), 133-160.

Chen, Yu-chin, and Kwok Ping Tsang, "Risk versus Expectations in Exchange Rates: A Macro-Finance Approach," University of Washington working paper (2009).

Chen, Yu-chin, Kwok Ping Tsang, and Wen Jen Tsay, "Home Bias in Currency Forecast," University of Washington working paper (2010).

Chinn, Menzie, "The (Partial) Rehabilitation of Interest Rate Parity: Longer Horizons, Alternative Expectations and Emerging Markets," Journal of International Money and Finance 25 (2006), 7-21.

Chinn, Menzie, and Guy Meredith, "Long-Horizon Uncovered Interest Rate Parity," IMF staff paper, 51:3 (2004).

Clarida, Richard H., Lucio Sarno, Mark P. Taylor, and Giorgio Valente, "The Out-of-Sample Success of Term Structure Models as Exchange Rate Predictors: A Step Beyond," Journal of International Economics 60 (2003), 61-83.

Clarida, Richard H., and Mark P. Taylor, "The Term Structure of Forward Exchange Premiums and the Forecastability of Spot Exchange Rates: Correcting the Errors," this REVIEW 79 (1997), 353-361.

Clarida, Richard, and Daniel Waldman, "Is Bad News about Inflation Good News for the Exchange Rate?" in John Y. Campbell (ed.), Asset Prices and Monetary Policy (Chicago: University of Chicago Press, 2008).

de los Rios, Antonio Diez, "Can Affine Term Structure Models Help Us Predict Exchange Rates?" Journal of Money, Credit and Banking 41 (2009), 755-766.
Dewachter, Hans, and Macro Lyrio, "Macro Factors and the Term Structure of Interest Rates," Journal of Money, Credit and Banking 38 (2006), 119-140.

Diebold, Francis X., C. Li, and Vivian Yue, "Global Yield Curve Dynamics and Interactions: A Generalized Nelson-Siegel Approach," Journal of Econometrics 146 (2008), 351-363.

Diebold, F. X., M. Piazzesi, and G. D. Rudebusch, "Modeling Bond Yields in Finance and Macroeconomics," American Economic Review 95 (2005), 415-420.

Diebold, F. X., G. D. Rudebusch, and B. Aruoba, "The Macroeconomy and the Yield Curve: A Dynamic Latent Factor Approach," Journal of Econometrics 131 (2006), 309-338.

Dornbusch, Rudiger, "Expectations and Exchange Rate Dynamics," Journal of Political Economy 84 (1976), 1161-1176.

Duffee, G. R., "Term Premia and Interest Rate Forecasts in Affine Models," Journal of Finance 57 (2002), 405-443.

Eichenbaum, Martin, and Charles L. Evans, "Some Empirical Evidence on the Effects of Shocks to Monetary Policy on Exchange Rates," Quarterly Journal of Economics 100 (1995), 975-1009.

Elliott, G., T. J. Rothenberg, \& J. H. Stock, "Efficient Tests for an Autoregressive Unit Root," Econometrica 64 (1996) 813-836.

Engel, Charles, "The Forward Discount Anomaly and the Risk Premium: A Survey of Recent Evidence," Journal of Empirical Finance 3 (1996), 123-192.

Engel, Charles, and Kenneth D. West, "Exchange Rates and Fundamentals," Journal of Political Economy 113 (2005), 485-517.

Estrella, Arturo, "Why Does the Yield Curve Predict Output and Inflation?” Economic Journal 115 (2005), 722-744.

Estrella, Arturo, and Frederic S. Mishkin, "Predicting U.S. Recessions: Financial Variables as Leading Indicators," this REVIEW 80 (1998), $45-61$.

Fama, Eugene F., "Forward and Spot Exchange Rates," Journal of Monetary Economics 14 (1984), 319-338.

Fama, Eugene, and Robert R. Bliss, "The Information in Long-Maturity Forward Rates," American Economic Review 77 (1987), 680-692.

Frankel, Jeffery, "On the Mark: A Theory of Floating Exchange Rates Based on Real Interest Differentials," American Economic Review 69 (1979), 610-623.

Frankel, Jeffery, and Andrew Rose, "Empirical Research on Nominal Exchange Rates" (pp. 1689-1729), in Gene Grossman and Kenneth Rogoff (eds.), Handbook of International Economics, vol. 3, (Amsterdam: Elsevier Science, 1995).

Froot, Kenneth, and Jeffrey Frankel, "Forward Discount Bias: Is It an Exchange Risk Premium?" Quarterly Journal of Economics 104 (1989), 139-161.

Gourinchas, Pierre-Olivier, and Aaron Tornell, "Exchange Rate Puzzles and Distorted Beliefs," Journal of International Economics 64 (2004), 303-333.

Hamilton, James D., and Dong Heon Kim, “A Reexamination of the Predictability of Economic Activity Using the Yield Spread," Journal of Money, Credit and Banking 34 (2002), 340-360.

Inci, Ahmet Can, and Biao, Lu, "Exchange Rates and Interest Rates: Can Term Structure Models Explain Currency Movements?" Journal of Economic Dynamics and Control 28 (2004), 1595-1624.

Krippner, Leo, "A Yield Curve Perspective on Uncovered Interest Parity," University of Waikato, Department of Economics working paper (2006).

Mark, Nelson C., "Exchange Rates and Fundamentals: Evidence on Long-Horizon Predictability," American Economic Review 85 (1995), 201-218.

Meese, R., and Kenneth S. Rogoff, "Empirical Exchange Rate Models of the Seventies: Do They Fit Out of Sample?" Journal of International Economics 14 (1983), 3-24.

Mishkin, Frederic, "What Does the Term Structure Tell Us about Future Inflation?" Journal of Monetary Economics 25 (1990a), 77-95.

"The Information in the Longer Maturity Term Structure about Future Inflation," Quarterly Journal of Economics 105 (1990b), $815-828$

Molodtsova, Tanya, Alex Nikolsko-Rzhevskyy, and David H. Papell, “Taylor Rules with Real-Time Data: A Tale of Two Countries and One Exchange Rate," Journal of Monetary Economics 55 (2008), 63-79.

Molodtsova, Tanya, and David H. Papell, "Out-of-Sample Exchange Rate Predictability with Taylor Rule Fundamentals," mimeograph, University of Houston (2008). 
Moon, Roger, Antonio Rubia, and Rossen Valkanov, "Long-Horizon Regressions When the Predictor Is Slowly Varying," University of California, San Diego working paper (2004).

Mussa, Michael, "The Exchange Rate, the Balance of Payments, and Monetary and Fiscal Policy under a Regime of Controlled Floating," Scandinavian Journal of Economics 78 (1976), 229248.

Nelson, Charles R., and Andrew F. Siegel, "Parsimonious Modeling of Yield Curves," Journal of Business 60 (1987), 473-489.

Pagan, Adrian, "Econometric Issues in the Analysis of Regressions with Generated Regressors," International Economic Review 25 (1984), 221-247.

Piazzesi, Monika, and Martin Schneider, "Equilibrium Yield Curves," NBER Macro Annual 21 (2006), 389-442.

Rogoff, Kenneth S., and Vania Stavrakeva, "The Continuing Puzzle of Short Horizon Exchange Rate Forecasting," NBER working paper 14071 (2008)

Rudebusch, Glenn D., and Tao Wu, “Accounting for a Shift in Term Structure Behavior with No-Arbitrage and Macro-Finance Models," Journal of Money, Credit and Banking 39 (2007), 395-422.
"A Macro-Finance Model of the Term Structure, Monetary Policy and the Economy," Economic Journal 118 (2008), 906-926.

Sarno, Lucio, "Viewpoint: Towards a Solution to the Puzzles in Exchange Rate Economics: Where Do We Stand?" Canadian Journal of Economics 38 (2005), 673-708.

Stock, James H., and Mark W. Watson, "Phillips Curve Inflation Forecasts," Conference Series [Proceedings], Federal Reserve Bank of Boston (2008).

Thornton, Daniel L., "Tests of the Expectations Hypothesis: Resolving the Campbell-Shiller Paradox," Journal of Money, Credit and Banking 38 (2006), 511-542.

Valkanov, Rossen, "Long-Horizon Regressions: Theoretical Results and Applications," Journal of Financial Economics 68 (2003), 201232.

Wang, Jian, and Jason J. Wu, "The Taylor Rule and Forecast Intervals for Exchange Rates," FRB International Finance discussion paper 963 (2009).

Wu, Shu, "Interest Rate Risk and the Forward Premium Anomaly in Foreign Exchange Markets," Journal of Money, Credit and Banking 39 (2007), 423-442. 